\title{
DYNAMICS OF LARGE MULTINATIONALS
}

\author{
Elhanan Helpman \\ Benjamin C. Niswonger \\ Working Paper 29317 \\ http://www.nber.org/papers/w29317 \\ NATIONAL BUREAU OF ECONOMIC RESEARCH \\ 1050 Massachusetts Avenue \\ Cambridge, MA 02138 \\ October 2021
}

We thank Pol Antràs, Natalia Ramondo, Assaf Razin and Stephen Yeaple for useful comments. The views expressed herein are those of the authors and do not necessarily reflect the views of the National Bureau of Economic Research.

NBER working papers are circulated for discussion and comment purposes. They have not been peer-reviewed or been subject to the review by the NBER Board of Directors that accompanies official NBER publications.

(C) 2021 by Elhanan Helpman and Benjamin C. Niswonger. All rights reserved. Short sections of text, not to exceed two paragraphs, may be quoted without explicit permission provided that full credit, including $\odot$ notice, is given to the source. 
Dynamics of Large Multinationals

Elhanan Helpman and Benjamin C. Niswonger

NBER Working Paper No. 29317

October 2021

JEL No. D43,F12,F23,L11,L13,L25

\begin{abstract}
$\underline{\text { ABSTRACT }}$
We develop a model of large multinational enterprises, each one producing a continuum of products. These outsized firms compete as oligopolists in a domestic and foreign market, facing competitive pressure from single-product firms that engage in monopolistic competition. The multinational enterprises invest in $\mathrm{R} \& \mathrm{D}$ in order to expand the span of their products and in foreign direct investment (FDI) in order to expand the range of products manufactured by their foreign affiliates. We study the dynamic evolution of these markets and characterize transition dynamics and steady states. In addition to the evolution of product spans, we characterize the evolution of prices, markups, market shares, and exports relative to subsidiary sales. Furthermore, we study comparative dynamics that result from changes in trade costs, R\&D costs, the cost of FDI and productivity changes of the multinational firms.
\end{abstract}

\author{
Elhanan Helpman \\ Department of Economics \\ Harvard University \\ 1875 Cambridge Street \\ Cambridge, MA 02138 \\ and CEPR \\ and also NBER \\ ehelpman@harvard.edu \\ Benjamin C. Niswonger \\ Harvard University \\ niswonger@g.harvard.edu
}




\section{Introduction}

Among the stylized facts described by Antras and Yeaple (2014) is the observation that only a quarter of goods sold to foreign customers by large American firms were domestically produced while three quarters were produced by foreign affiliates of American multinational corporations. In addition, about $90 \%$ of U.S. imports and exports streamed through these companies.

In the August 21, 2020 news release "Activities of U.S. Multinational Enterprises, 2018," the Bureau of Economic Analysis (BEA) reports that worldwide employment of these companies was 43 million workers, with about one third employed abroad by majority-owned foreign affiliates, and their worldwide value-added was $\$ 5.7$ trillion.

U.S. multinational enterprises (MNEs) play an oversized role in the world economy in terms of both trade and production. But they also play a big role in research and development (R\&D) and they are relatively more active in R\&D intensive sectors (see Antras and Yeaple (2014)). According to the BEA report, in 2018 American MNEs spent $\$ 381.4$ billion on $\mathrm{R} \& \mathrm{D}$, with only $\$ 58.2$ billion accounted for by majority-owned foreign affiliates. More generally, within multinationals parents are relatively specialized in $R \& D$ while their subsidiaries are relatively specialized in serving foreign markets, and chiefly their host countries. Finally, both parents and subsidiaries tend to be larger, more productive, and more R\&D intensive than non-multinational firms (see Antras and Yeaple (2014)).

There has been growing interest in studying innovation and multinational production. Most of this work has been designed for quantitative analysis, however, abstracting from firm dynamics. Arkolakis et al. (2018) provide a good example. Like us, they treat innovation as a process for creating new goods, but, unlike us, they assume that every firm specializes in a single product and its innovation consists of a one-time acquisition of this product. Otherwise, their quantitative model is static but rich in other dimensions; e.g., it has many countries and platform FDI. A firm that enters the industry draws a vector of productivities in which every entry applies to a different country and the analysis emphasizes relative specialization in innovation or production.

A quantitative model with similar features, but with firm dynamics, is developed in Garetto et al. (2021). Their firms draw time-invariant firm-specific productivities, which are subsequently augmented by time-varying country-specific shocks. The latter follow exogenous processes that feed the system's dynamics. In this model, a firm that builds a foreign subsidiary acquires an option to sell in the host market as well as an option to export to other countries. ${ }^{1}$

In contrast to these papers, our model is stylized in its geographic structure. But this is compensated for by modeling multinational corporations as large multi-product firms with oligopolistic market power, as they indeed are. Moreover, we treat innovation and FDI as investment activities that gradually expand an MNE's range of products and the span of products available to its foreign affiliates, respectively. Both investments involve sunk costs. Our goal is to study the dynamic

\footnotetext{
${ }^{1}$ Gumpert et al. (2020), a predecessor to Garetto et al. (2021), extends the static heterogeneous firms model of Helpman et al. (2004) by assuming that every firm's productivity evolves according to a Markov process. They focus on the life-cycle of exporters and MNEs, using a simple spacial structure with no platform FDI.
} 
evolution of such firms in a world economy in which they play an outsized role. For this purpose we model them as oligopolists who face competition from a fringe of monopolistically competitive single-product firms, building on the closed-economy model of Helpman and Niswonger (2021). These MNEs serve foreign markets with exports and subsidiary sales and they use market power to price to market, charging different prices at home and abroad.

Consistent with the evidence, our model features short-lived small single-product firms and longlived large multi-product corporations. Cao et al. (2019) report that $95 \%$ of U.S. firms had single establishments while their share in employment was 45\%. During 1972-2007 an average of $72 \%$ of plants in manufacturing belonged to single-plant firms, but these firms produced only $22 \%$ of value added (see Table A1 in Kehrig and Vincent (2019)). These data suggest the existence of a competitive fringe faced by large multi-product MNEs. ${ }^{2}$ These studies also report that firm growth took place mostly through the extensive margin, which we embody into our analytical framework.

Some basic features of our model are described in Section 2. Preferences are quasi-linear, there is one factor of production, labor, and two sectors: one producing a homogeneous good the other producing varieties of a differentiated product. As is common, wages are determined in the homogenous sector. Individuals have CES preferences for varieties of the differentiated product. There are two countries, home and foreign, but only the former is home to large multi-product firms.

Section 3 describes an instantaneous equilibrium of the world economy that holds at each point in time. In every instant the firms play a two-stage game, taking as given the number of products owned by every multi-product firm and the number of products available to their foreign affiliates. First, single-product firms enter, expecting to survive one instant only. In the second stage, all firms play a Bertrand price game. For simplicity, we assume that single-product firms serve only their domestic markets. In contrast, multi-product firms sell at home and abroad, and they can serve the foreign market with exports or foreign affiliates. Exports entail melting iceberg costs.

In Section 4 we analyze the evolution of FDI, assuming that every large firm has a constant product span, while in Section 5 we analyze the joint evolution of FDI and product span. The intermediate case of foreign direct investment with constant product spans enables us to fully characterize the growth of MNEs, including transition dynamics. It also provides valuable insights that are difficult to see in the more complex case of joint FDI and innovation.

Our model generates rich dynamics that produce non-monotonicities in the time series and in the cross-section. To illustrate, an increase in export costs reduces on impact prices charged by foreign subsidiaries, their markups, and the foreign market shares of the MNEs. But this one-time adjustment is followed by a subsequent gradual rise of foreign prices, markups and market shares. Despite that, exports relative to subsidiary sales grow throughout, in line with the proximityconcentration tradeoff theory of foreign direct investment. A reduction of FDI costs also produces results consistent with this theory. Especially interesting is the finding that whenever the multiproduct MNEs differ in labor productivity, the cross-sectional relationship between exports relative

\footnotetext{
${ }^{2}$ Shimomura and Thisse (2012) study the interactions between a monopolistically competitive fringe of singleproduct firms and oligopolistic large firms in a static closed economy, while Parenti (2018) studies such interactions in a static open economy without MNEs.
} 
to subsidiary sales and labor productivity is non-monotonic. A summary of our main results is provided in Section 6.

\section{Preliminaries}

We consider a world consisting of two countries, a home country $H$ and a foreign country $F$. In every country, there is a continuum of individuals of mass one. Labor markets are competitive and within a country, every individual earns the same wage rate.

There are two sectors. One sector produces a tradable homogeneous good with one unit of labor per unit output and this technology is available in both countries. Demand for the homogeneous good is always high enough to secure positive production in $H$ and $F$. For this reason in every country the wage rate equals the price of the homogeneous good. We normalize this price to equal one and therefore wages equal one in both countries. The other sector produces varieties of a differentiated product. ${ }^{3}$

Every individual supplies a fixed amount of labor, $l$, and has a utility function ${ }^{4}$

$$
u=x_{0}+\frac{\varepsilon}{\varepsilon-1}\left[\int_{\omega \in \Omega} x(\omega)^{\frac{\sigma-1}{\sigma}} d \omega\right]^{\frac{(\varepsilon-1) \sigma}{\varepsilon(\sigma-1)}}, \sigma>\varepsilon>1,
$$

where $x_{0}$ is consumption of the homogeneous good, $x(\omega)$ is consumption of variety $\omega$ of the differentiated product, $\Omega$ is the set of available varieties, $\sigma$ is the elasticity of substitution between varieties and $\varepsilon$ gauges the degree of substitutability between varieties of the differentiated product and the homogeneous good. The assumption $\sigma>\varepsilon$ asserts that brands of the differentiated product are better substitutes for each other than for the homogeneous good. The assumption $\varepsilon>1$ ensures that aggregate spending on the differentiated product declines when its price rises (see below).

Real consumption of the differentiated product is

$$
X=\left[\int_{\omega \in \Omega} x(\omega)^{\frac{\sigma-1}{\sigma}} d \omega\right]^{\frac{\sigma}{\sigma-1}}
$$

Consequently, the price index of $\mathrm{X}$ is

$$
P=\left[\int_{\omega \in \Omega} p(\omega)^{1-\sigma} d \omega\right]^{\frac{1}{\sigma-1}}
$$

where $p(\omega)$ is the price of variety $\omega$.

Every individual chooses consumption to maximize utility subject to the budget constraint $x_{0}+P X=l+y$, where $y$ is non-wage income (this income will differ across countries). This yields $X=P^{-\varepsilon}$ as long as consumers purchase the homogenous good and varieties of the differentiated product, which we assume always to be the case (this requires $l$ to be large enough). In this case,

\footnotetext{
${ }^{3}$ It is straightforward to generalize the analysis to multiple sectors with differentiated products, or to differences in labor productivity in the homogeneous sector that lead to wage differences across countries.

${ }^{4}$ We can allow $l$ to vary across countries, but this variation will not affect our results.
} 
the demand for variety $\omega$ is independent of $y$ and equal to

$$
x(\omega)=P^{\delta} p(\omega)^{-\sigma}, \delta=\sigma-\varepsilon>0 .
$$

Aggregate spending on the differentiated product equals $P X=P^{1-\varepsilon}$, which declines in $P$ (because $\varepsilon>1) .^{5}$

In the foreign country, the differentiated product sector is populated by single product firms that require $f$ units of labor to enter the industry and $a$ units of labor per unit output for manufacturing brands of the differentiated product. These firms serve only the domestic market. ${ }^{6}$ After entry, every single-product firm maximizes profits, $P_{F}^{\delta} p(\omega)^{-\sigma}[p(\omega)-a]$, taking as given the demand function (2) and the price index in country $F, P_{F}$. This results in the price

$$
p=\frac{\sigma}{\sigma-1} a
$$

for domestic sales. We denote by $n_{F}>0$ the number of single-product firms in country $F$, each one supplying a distinct brand of the product.

In country $H$, two types of firms operate in the differentiated product sector: atomless singleproduct firms and $I$ large multi-product firms. Every large firm has a positive measure of product lines, $n_{i}, i=1,2, \ldots, I$. As in country $F$, all single-product firms share the same technology, which requires $f$ units of labor for entry and $a$ units of labor per unit output. ${ }^{7}$ They serve only the home country. After entry a single-product firm maximizes profits, $P_{H}^{\delta} p(\omega)^{-\sigma}[p(\omega)-a]$, subject to the demand function (2), taking as given the price index in country $H, P_{H}$. As a result, similar to country $F$ single-product firms, every single-product firm in $H$ charges the price $p$, given by (3). We denote by $n_{H}$ the number of brands produced by single-product firms in country $H$.

While country $F$ has no large multi-product firms, multi-product firm $i$ in country $H$ has a technology for producing $n_{i}>0$ varieties, each one with $a_{i}$ units of labor per unit output. This technology can be used to produce each one of the $n_{i}$ products at home or each one of $m_{i}<n_{i}$ products abroad, where $m_{i}$ is the product span of the firm's foreign subsidiaries that has been acquired through foreign direct investments (FDI). ${ }^{8}$ That is, every multi-product firm is a multinational enterprise (MNE). For now, we take both $n_{i}$ and $m_{i}$ as given in order to examine momentary equilibria. In Section 4 we will introduce investment in foreign subsidiaries and study dynamics of FDI that determine the time pattern of $m_{i}$ for a given product span $n_{i}$. In the following Section 5 we

\footnotetext{
${ }^{5}$ An individual's consumption choice yields the indirect utility function

$$
v=l+y+\frac{1}{\varepsilon-1} P^{1-\varepsilon}
$$

where the third term on the right-hand side represents consumer surplus.

${ }^{6}$ Assuming that small firms serve only the domestic market simplifies the algebra. What's more, this assumption is consistent with the evidence; few small firms export and even fewer engage in foreign direct investment. We make below a similar assumption with regard to small firms in country $H$.

${ }^{7}$ We could allow the technologies of single-product firms to vary across countries without affecting our main results.

${ }^{8}$ Many recent quantitative models of multinational production introduce heterogenous productivities in different geographical locations, in order to handle platform FDI; see, for example, Garetto et al. (2021). Since we do not deal with platform FDI, we adopt the simplifying assumption of equal productivities at home and abroad.
} 
will also introduce investment in innovation that expands the number of products $n_{i}$ and investigate the joint evolution of $n_{i}$ and $m_{i}$, focusing on properties of the long-run equilibrium.

Evidently, MNE $i$ is not of measure zero and it does not take as given the price indexes $P_{J}$, $J=F, H$. Because wages are the same in the two countries, firm $i$ serves the foreign market with $m_{i}$ varieties via subsidiary sales and with $n_{i}-m_{i}$ varieties via exports. Exports are costly and we denote with $\tau-1>0$ the per unit export cost. That is, it takes $\tau$ units of a product to ship to the foreign country for one unit to arrive. We also use $p_{i}$ to denote the price firm $i$ charges for a product sold in the home market, $p_{e, i}$ for the price charged for an exported product in the foreign market, and $p_{m, i}$ for the price charged in the foreign market by the firm's foreign affiliates. Using this notation, the price indexes are

$$
\begin{gathered}
P_{F}=\left[n_{F} p^{1-\sigma}+\sum_{k=1}^{I}\left(n_{k}-m_{k}\right) p_{e, k}^{1-\sigma}+\sum_{k=1}^{I} m_{k} p_{m, k}^{1-\sigma}\right]^{\frac{1}{1-\sigma}}, \\
P_{H}=\left[n_{H} p^{1-\sigma}+\sum_{k=1}^{I} n_{k} p_{k}^{1-\sigma}\right]^{\frac{1}{1-\sigma}} .
\end{gathered}
$$

At each point in time, the firms play a two-stage game. In the first stage single-product firms enter. This yields $n_{F}$ and $n_{H}$ that are taken as given in stage two, and we assume that both are always positive. In stage two, every firm chooses its prices taking as given pricing policies of its rivals. The subgame perfect equilibrium of this two stage game constitutes the instantaneous equilibrium at a point in time; it is characterized in the next section.

\section{Instantaneous Equilibrium}

To study the instantaneous equilibrium, we begin with the second stage of the game, in which $n_{F}$ and $n_{H}$ are given (and so are $n_{i}$ and $m_{i}$ for $i=1,2, \ldots, I$ ). At this stage the firms play a Bertrand game: every firm chooses its prices given the pricing policies of all other firms. This implies that all single product firms charge $p$ to their domestic customers (see (3)).

Large multi-product firms recognize the impact of their pricing policy on the price indexes $P_{F}$ and $P_{H}$. For this reason firm $i$, which seeks to maximize profits, solves the following problem:

$$
\max _{p_{i}, p_{e, i}, p_{m, i}} n_{i} P_{H}^{\delta} p_{i}^{-\sigma}\left(p_{i}-a_{i}\right)+\left(n_{i}-m_{i}\right) P_{F}^{\delta} p_{e, i}^{-\sigma}\left(p_{e, i}-\tau a_{i}\right)+m_{i} P_{F}^{\delta} p_{m, i}^{-\sigma}\left(p_{m, i}-a_{i}\right)
$$

subject to (4)-(5). The solution to this problem yields the following prices:

$$
\begin{gathered}
p_{i}=\frac{\sigma-\delta s_{i}}{\sigma-\delta s_{i}-1} a_{i}, \\
p_{e, i}=\frac{\sigma-\delta s_{F, i}}{\sigma-\delta s_{F, i}-1} \tau a_{i},
\end{gathered}
$$




$$
p_{m, i}=\frac{\sigma-\delta s_{F, i}}{\sigma-\delta s_{F, i}-1} a_{i}
$$

where $s_{i}$ is the market share of firm $i$ in $H$ and $s_{F, i}$ is its combined market share in $F$, from exports and subsidiary sales, and (see appendix for details)

$$
\begin{gathered}
s_{i}=\frac{n_{i} p_{i}^{1-\sigma}}{P_{H}^{1-\sigma}}=\frac{n_{i} p_{i}^{1-\sigma}}{n_{H} p^{1-\sigma}+\sum_{k=1}^{m} n_{k} p_{k}^{1-\sigma}}, \\
s_{F, i}=\frac{\left(n_{i}-m_{i}\right) p_{e, i}^{1-\sigma}+m_{i} p_{m, i}^{1-\sigma}}{P_{F}^{1-\sigma}} \\
=\frac{\left(n_{i}-m_{i}\right) p_{e, i}^{1-\sigma}+m_{i} p_{m, i}^{1-\sigma}}{n_{F} p^{1-\sigma}+\sum_{k=1}^{m}\left(n_{i}-m_{i}\right) p_{e, k}^{1-\sigma}+\sum_{k=1}^{m} m_{k} p_{m, k}^{1-\sigma}} .
\end{gathered}
$$

Equations (6)-(10) jointly determine prices and market shares of large firms, given $n_{F}, n_{H}$ and $\left\{n_{i}, m_{i}\right\}$. Note that (7) and (8) imply $p_{e, i}=\tau p_{m, i}$. Namely, every large firm charges for its exports a price that is $\tau$ times higher than the price for its subsidiary sales.

Recall from the price charged by single-product firms, $p$, that these firms' markup factor is $\sigma /(\sigma-1)$ (see (3)). In contrast, the markup factors of firm $i$ are $\left(\sigma-\delta s_{i}\right) /\left(\sigma-\delta s_{i}-1\right)$ in the domestic market and $\left(\sigma-\delta s_{F, i}\right) /\left(\sigma-\delta s_{F, i}-1\right)$ in the foreign market. The latter applies to exports and subsidiary sales (see (6)-(8)). Evidently, the MNE's markups are increasing in market shares; the markup in the domestic market is rising with the firm's domestic market share while its markup in the foreign country is rising with the firm's foreign market share. When a market share equals zero, the markup is $\sigma /(\sigma-1)$, the same as the markup of a single-product firm. The domestic markups vary across firms as a result of differences in either the product span, $n_{i}$, or the marginal production cost, $a_{i}$, while the foreign markups vary across firms as a result of differences in $n_{i}, a_{i}$ and product spans of foreign subsidiaries, $m_{i}$.

This system of equations is separable. Prices and market shares of sales in $H$ can be solved with equations (6) and (9) only while prices and market shares of sales in country $F$ can be solved with equations (7), (8) and (10) only. Firm $i$ 's exports relative to subsidiary sales are given by

$$
\rho_{i}=\tau^{1-\sigma} \frac{n_{i}-m_{i}}{m_{i}}
$$

These measures are central to the proximity-concentration tradeoff theory of foreign direct investment. We will examine the consistency of our model with this theory in the next section. ${ }^{9}$

We now turn to the first stage of the game. Unlike large multi-product firms, single-product firms enter the industry until their profits equal zero. They are short lived. In particular, they live a

\footnotetext{
${ }^{9}$ Aggregate exports relative to aggregate subsidiary sales are given by

$$
\rho=\tau^{1-\sigma} \frac{\sum_{i=1}^{I}\left(n_{i}-m_{i}\right) p_{m, i}^{1-\sigma}}{\sum_{i=1}^{I} m_{i} p_{m, i}^{1-\sigma}}=\sum_{i=1}^{I} \kappa_{i} \rho_{i}
$$
}


single instant. A single-product firm correctly forecasts the price indexes $P_{F}$ and $P_{H}$ that will exist in the second stage of the game, and it understands that it cannot affect them. It also correctly forecasts the price it will charge for its product in the second stage of the game. For these reasons, free entry leads to operating profits that equal entry cost. For single-product firms in countries $H$ and $F$ this implies

$$
\frac{1}{\sigma} P_{J}^{\delta}\left(\frac{\sigma}{\sigma-1} a\right)^{1-\sigma}=f, J=H, F
$$

where the left-hand side describes the operating profits from sales in country $J$, equal to fraction $1 / \sigma$ of revenue, while the right-hand side represents entry costs. Taken together, these free entry conditions imply that $P_{F}=P_{H}=P$, where $P$ satisfies

$$
\frac{1}{\sigma} P^{\delta}\left(\frac{\sigma}{\sigma-1} a\right)^{1-\sigma}=f .
$$

In these circumstances, $P$ is determined by the technological parameters of single-product firms, $f$ and $a$, and it is rising in both of them. Importantly, $P$ does not depend on the number of large firms, their product spans nor the spans of their subsidiaries.

Since the price index $P$ is constant and the same in both countries, (6) and (9) provide solutions to the domestic price and market share in country $H, p_{i}$ and $s_{i}$, respectively, as functions of the product span $n_{i}$. We denote these functions by $p_{i}\left(n_{i}\right)$ and $s_{i}\left(n_{i}\right)$ and note that they are increasing in $n_{i}$. They also depend on the firm's labor productivity $1 / a_{i}$ and the price index $P$, although for now we emphasize their dependence on product span only. Moreover, (8) and (10) together with $p_{e, i}=\tau p_{m, i}$ provide solutions to the foreign price and foreign market share as functions of $n_{i}$ and $m_{i}$, which we denote by $p_{m, i}\left(n_{i}, m_{i}\right)$ and $s_{F, i}\left(n_{i}, m_{i}\right)$, respectively. These functions also depend on $1 / a_{i}$ and $P$. Properties of these functions are elaborated in the appendix. We show that

$$
\begin{aligned}
& p_{m, i}\left(n_{i}, m_{i}\right)=p_{i}\left[\left(n_{i}-m_{i}\right) \tau^{1-\sigma}+m_{i}\right], \\
& s_{F, i}\left(n_{i}, m_{i}\right) \equiv s_{i}\left[\left(n_{i}-m_{i}\right) \tau^{1-\sigma}+m_{i}\right],
\end{aligned}
$$

where $p_{i}(\cdot)$ and $s_{i}(\cdot)$ are the domestic price and market share functions. We interpret $n_{F, i} \equiv$ $\left(n_{i}-m_{i}\right) \tau^{1-\sigma}+m_{i}$ as the effective number of products in the foreign market, where the number of exported goods is discounted by the trade cost statistic $\tau^{1-\sigma}$. In the absence of trade costs or when the firm's foreign subsidiaries manufacture its entire product span, $n_{F, i}=n_{i}$, the firm charges at home the same price that its subsidiaries charge abroad, its market shares are the same in both countries and so are its markups. Otherwise the effective number of products in the foreign market is smaller than $n_{i}$, as we assume. We therefore have

where

$$
\kappa_{i}=\frac{m_{i} p_{m, i}^{1-\sigma}}{\sum_{k=1}^{I} m_{k} p_{m, k}^{1-\sigma}}
$$

That is, aggregate exports relative to subsidiary sales are a weighted average of exports relative to subsidiary sales of the multinational firms. 
Proposition 1. The price charged by MNE $i$ 's foreign affiliates is lower than the domestic price, $p_{m, i}<p_{i}$, the foreign market share is smaller than the domestic market share, $s_{F, i}<s_{i}$, and markups of exporters and foreign subsidiaries are smaller than the domestic markup.

One may conclude from this proposition that large firms discriminate between domestic and foreign markets, because - despite facing comparable cost and demand structures - foreign subsidiaries charge lower prices than their parents at home. And indeed they do. The difference in treatment stems from the fact that only a fraction of a firm's products are manufactured abroad while the remaining fraction is exported. Despite the presence of export costs, the firm's best strategy is to maintain parity between its markups on exports and subsidiary sales and keep them lower than the domestic markup. The resulting foreign market share is lower than the domestic market share.

\section{FDI Dynamics}

In this section, we examine the dynamics of foreign direct investment of a large firm $i$ that has an unalterable product $\operatorname{span} n_{i}$. The analysis of these dynamics is greatly aided by the free entry conditions of single-product firms, which secure a constant price index $P$ on the dynamic path (see (12)). To this end we assume that small single-product firms enter the industry in both countries, at each point in time (i.e., $n_{F}>0$ and $n_{H}>0$ on every equilibrium path).

We now endow firm $i$ with an investment technology that expands the product span of its subsidiaries, but we also assume that a fraction $\theta$ of $m_{i}$ is destroyed per unit time. ${ }^{10}$ In particular, we assume that the change in the product span of subsidiaries follows the differential equation

$$
\dot{m}_{i}=\phi_{m}\left(\iota_{m, i}\right)-\theta m_{i}
$$

where $\iota_{m, i}$ is foreign direct investment and $\phi_{m}\left(\iota_{m, i}\right)$ is gross addition to the firm's foreign product span per unit time. ${ }^{11}$ All the variables in this equation are time dependent, although we have suppressed the time index for simplicity. We assume that the function $\phi_{m}(\iota)$ is increasing, concave, $\phi_{m}(0)=0$ and it satisfies the Inada conditions $\lim _{\iota \rightarrow 0} \phi_{m}^{\prime}(\iota)=+\infty$ and $\lim _{\iota \rightarrow+\infty} \phi_{m}^{\prime}(\iota)=0$.

Next assume that the interest rate is constant and equal to $r .{ }^{12}$ Firm $i$ maximizes the discounted present value of profits. However, as long as $n_{i}$ is constant there is no dynamic decision regarding the present value of profits from domestic sales. For a constant $P$, equations (6) and (9) provide solutions to the domestic price and market share that depend on the firm's product span, $p_{i}\left(n_{i}\right)$

\footnotetext{
${ }^{10}$ We do not take a position on how many subsidiaries the firm has in the foreign country, because for our purposes only the size of $m_{i}$ matters. For example, one can think about $m_{i}$ as the number of plants owned by firm $i$, each one producing a different variety and each one owned by a different subsidiary, or an organizational form in which all plants are owned by a single subsidiary

${ }^{11}$ The variable $\iota_{m, i}$ does not correspond to the size of FDI in balance of payments statistics. The latter represents financial flows while our variable represents real investment in new product lines, independently of financing sources.

${ }^{12} \mathrm{~A}$ constant interest rate can be derived from the assumption that consumers maximize the expected present value of utility subject to their budget constraints. Due to the quasi-linearity of the utility function, this yields an interest rate equal to the consumers' subjective discount rate.
} 
and $s_{i}\left(n_{i}\right)$, respectively, which are increasing functions of $n_{i} \cdot{ }^{13}$ Consequently, domestic prices and market shares of large firms do not change over time, and neither do their domestic markups. For these reasons, the only dynamic problem of a large firm is to maximize the present value of profits from foreign sales net of FDI costs. Therefore, firm $i$ solves the following optimal control problem:

$$
\max _{\left\{\iota_{m, i}(t), m_{i}(t)\right\}_{t \geq 0}} \int_{0}^{\infty} e^{-r t} \pi_{F, i}\left[\iota_{m, i}(t), m_{i}(t)\right] d t
$$

subject to (15),

$$
\pi_{F, i}\left(\iota_{m, i}, m_{i}\right)=P^{\delta}\left[\left(n_{i}-m_{i}\right) \tau^{1-\sigma}+m_{i}\right] p_{m, i}\left(n_{i}, m_{i}\right)^{-\sigma}\left[p_{m, i}\left(n_{i}, m_{i}\right)-a_{i}\right]-\iota_{m, i}, \text { for all } t \geqslant 0,
$$

the initial condition $m_{i}(0)=m_{i}^{0}$ and a transversality condition to be described below. In this problem $\iota_{m, i}$ is a control variable while $m_{i}$ is a state variable.

The current-value Hamiltonian of this problem is

$$
\begin{aligned}
\mathcal{H}\left(\iota_{m, i}, m_{i}, \zeta_{m, i}\right) & =P^{\delta}\left[\left(n_{i}-m_{i}\right) \tau^{1-\sigma}+m_{i}\right] p_{m, i}\left(n_{i}, m_{i}\right)^{-\sigma}\left[p_{m, i}\left(n_{i}, m_{i}\right)-a_{i}\right] \\
& +\zeta_{m, i}\left[\phi_{m}\left(\iota_{m, i}\right)-\theta m_{i}\right]-\iota_{m, i}
\end{aligned}
$$

where $\zeta_{m, i}$ is the co-state variable of (15). Since this Hamiltonian is concave in $\iota_{m, i}$ and $m_{i}$ (see below), a dynamic path that satisfies the first-order conditions and the transversality condition maximizes the present value of foreign profits net of FDI costs. The first-order conditions of this optimal control problem are

$$
\begin{gathered}
\frac{\partial \mathcal{H}}{\partial \iota_{m, i}}=\zeta_{m, i} \phi_{m}^{\prime}\left(\iota_{m, i}\right)-1=0, \\
-\frac{\partial \mathcal{H}}{\partial m_{i}}=-\frac{\partial \pi_{F, i}}{\partial m_{i}}+\zeta_{m, i} \theta=\dot{\zeta}_{m, i}-r \zeta_{m, i},
\end{gathered}
$$

and the transversality condition is

$$
\lim _{t \rightarrow \infty} e^{-r t} \zeta_{m, i}(t) m_{i}(t)=0
$$

In addition, the optimal path has to satisfy the differential equation (15), starting at $m_{i}^{0}$. We show in the appendix that

$$
\frac{\partial \pi_{F, i}}{\partial m_{i}}=\left(1-\tau^{1-\sigma}\right) \Lambda_{i}\left[s_{F, i}\left(n_{i}, m_{i}\right)\right]
$$

where

$$
\Lambda_{i}(s) \equiv\left(\frac{\sigma-\delta s}{\sigma-\delta s-1}\right)^{-\sigma} \frac{a_{i}^{1-\sigma} P^{\delta} \sigma}{(\sigma-\delta s-1) \sigma+(s \delta)^{2}}
$$

is a decreasing function, i.e., $\Lambda_{i}^{\prime}(s)<0$. Clearly, $\left(1-\tau^{1-\sigma}\right) \Lambda_{i}\left[s_{F, i}\left(n_{i}, m_{i}\right)\right]$ represents marginal profits of the product span of foreign subsidiaries. It is declining in the foreign market share and

\footnotetext{
${ }^{13}$ These functions also depend on $a_{i}$ and $P$; see appendix for their properties.
} 
rising in the variable export cost $\tau$. As is evident from (14), however, the foreign market share also depends on export costs. For this reason, the total impact of $\tau$ on marginal profitability of $m_{i}$ combines the direct and indirect effects. Since both are positive, we conclude that marginal profits of $m_{i}$ are rising in $\tau$. Furthermore, since (14) implies that the foreign market share is increasing in $n_{i}$ and $m_{i}$, we obtain ${ }^{14}$

Lemma 1. Marginal profits of the foreign product span $m_{i}$ satisfy

$$
\frac{\partial \pi_{F, i}}{\partial m_{i}}=\left(1-\tau^{1-\sigma}\right) \Lambda_{i}\left\{s_{i}\left[\left(n_{i}-m_{i}\right) \tau^{1-\sigma}+m_{i}\right]\right\} .
$$

They are increasing in $\tau$ and decreasing in $n_{i}$ and $m_{i}$.

An important property of marginal profits of foreign subsidiaries emerges from this lemma: other things equal, a large firm finds marginal profits of foreign direct investment less attractive the larger is the array of its varieties, $n_{i}$. This substitutability property plays an important role in what follows.

The above first-order conditions of the optimal control problem can be expressed as:

$$
\begin{gathered}
\zeta_{m, i} \phi_{m}^{\prime}\left(\iota_{m, i}\right)=1, \\
\dot{\zeta}_{m, i}=(r+\theta) \zeta_{m, i}-\left(1-\tau^{1-\sigma}\right) \Lambda_{i}\left\{s_{i}\left[\left(n_{i}-m_{i}\right) \tau^{1-\sigma}+m_{i}\right]\right\} .
\end{gathered}
$$

Using $\zeta_{m, i} \phi_{m}^{\prime}\left(\iota_{m, i}\right)=1$ to solve the FDI level

$$
\iota_{m, i}=\varphi_{m}\left(\zeta_{m, i}^{-1}\right)
$$

where $\varphi_{m}(\cdot)$ is the inverse of $\phi_{m}^{\prime}(\cdot)$, and substituting the result into (15) yields the differential equation

$$
\dot{m}_{i}=\phi_{m}\left[\varphi_{m}\left(\zeta_{m, i}^{-1}\right)\right]-\theta m_{i} .
$$

Equations (17) and (18) represent an autonomous system of two differential equations with one initial condition, $m_{i}^{0}$, and a free choice of $\zeta_{m, i}(0)$. They yield the steady state conditions

$$
\begin{gathered}
(r+\theta) \zeta_{m, i}=\left(1-\tau^{1-\sigma}\right) \Lambda_{i}\left\{s_{i}\left[\left(n_{i}-m_{i}\right) \tau^{1-\sigma}+m_{i}\right]\right\}, \\
\phi_{m}\left[\varphi_{m}\left(\zeta_{m, i}^{-1}\right)\right]=\theta m_{i} .
\end{gathered}
$$

Note that in the steady state the co-state variable $\zeta_{m, i}$ represents the discounted present value of marginal profits of the foreign product span, where future profits are discounted with the interest rate, $r$, plus the rate of depreciation, $\theta$. The discounted present value of marginal profits induces in turn an FDI level that compensates for the attrition of the foreign product span, so that $m_{i}$ does not change.

\footnotetext{
${ }^{14}$ This lemma shows that the Hamiltonian is concave in $m_{i}$. It is also concave in $\iota_{m, i}$ due to concavity of the FDI function $\phi_{m}\left(\iota_{m, i}\right)$.
} 


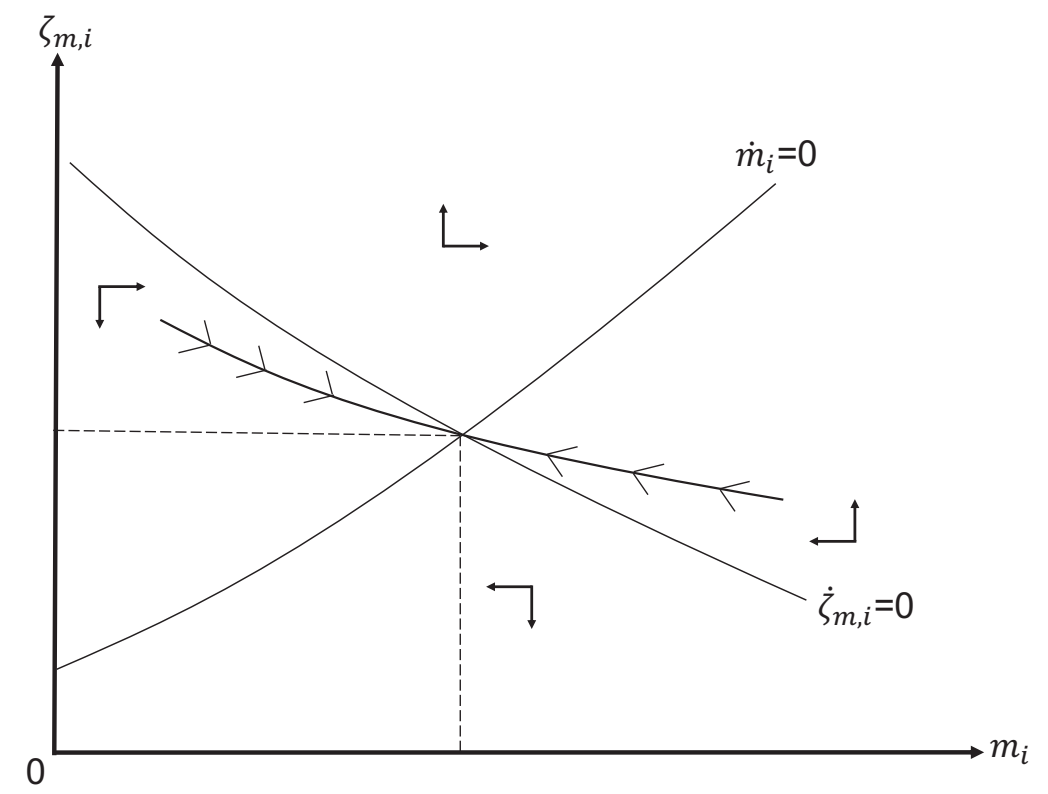

Figure 1: Transition Dynamics

The transversality condition is satisfied when the dynamic path converges to a steady state and Figure 1 describes such an equilibrium path, where the curve $\dot{\zeta}_{m, i}=0$ satisfies (19) and the curve $\dot{m}_{i}=0$ satisfies (20). This path is saddle-path stable. Starting with an initial $m_{i}^{0}$ the co-state variable $\zeta_{m, i}$ acquires at time zero a value that positions the differential equations on the saddle path. When $m_{i}(0)$ is below its steady state value, $m_{i}$ rises over time and $\zeta_{m, i}$ declines. In the opposite case, when $m_{i}(0)$ is above its steady state value, $m_{i}$ declines over time and $\zeta_{m, i}$ rises. Since the foreign market share - which combines exports and subsidiary sales - is an increasing function of the foreign product span, these dynamics imply that the foreign market share and foreign markup rise when $m_{i}$ increases and decline when $m_{i}$ declines. In contrast, the domestic market share and markup do not change. We therefore have

Proposition 2. Suppose that $n_{i}$ is constant. Then: (i) if $m_{i}(0)$ is below its steady value, $m_{i}$ rises during the transition and so do the foreign price, markup, market share and exports relative to subsidiary sales; (ii) if $m_{i}(0)$ is above its steady value, $m_{i}$ declines during the transition and so do the foreign price, markup, market share and exports relative to subsidiary sales; (iii) there are no changes in the domestic price, markup and market share.

\subsection{Comparative Dynamics}

In this section, we study the response of MNE $i$ to parameter changes. We begin with export costs. An increase in $\tau$ shifts upward the $\dot{\zeta}_{m, i}=0$ curve (because the right-hand side of (19) is rising in $\tau$ ) and does not alter the $\dot{m}_{i}=0$ curve. In response, $\zeta_{m, i}$ jumps upward on impact to the new transition path on which $m_{i}$ rises and $\zeta_{m, i}$ declines over time. In the new steady state foreign 
subsidiaries manufacture a larger set of products and fewer products are exported from the home country. During the transition, firm $i$ gradually exports less relative to subsidiary sales, in line with the proximity-concentration tradeoff theory of foreign direct investment. ${ }^{15}$

Next, consider a productivity improvement that reduces FDI costs. This can be represented by an upward shift in a variable $z_{m}$, starting with $z_{m}=1$, where we replace the function $\phi_{m}(\iota)$ with $z_{m} \phi_{m}(\iota)$. This shift has no impact on the $\dot{\zeta}_{m, i}=0$ curve, but it shifts rightward the $\dot{m}_{i}=0$ curve. ${ }^{16}$ As a result, $\zeta_{m, i}$ jumps down on impact and sets off a dynamic trajectory on which $m_{i}$ rises and $\zeta_{m, i}$ declines over time. We conclude that in this case too every MNE gradually reduces exports relative to subsidiary sales. We summarize these findings in

Proposition 3. Suppose that $n_{i}$ is constant for $i=1,2, \ldots, I$, and every $M N E$ is in a steady state. Then: (i) MNE $i$ responds to an increase in export costs by (a) reducing on impact prices charged by its foreign affiliates, foreign markups, the foreign market share, and the firm's exports relative to subsidiary sales; (b) subsequently gradually increasing the foreign product span, foreign prices, foreign markups, the foreign market share, and reducing exports relative to subsidiary sales. (ii) MNE $i$ responds to a productivity improvement in FDI by (a) gradually increasing its foreign product span, foreign prices, foreign markups, the foreign market share, and reducing exports relative to subsidiary sales. (iii) In both cases there are no changes in domestic prices, markups and market share.

We next examine two further variations: in the product span of firm $i, n_{i}$, and in its labor productivity, $1 / a_{i}$. First consider a one-time increase in $n_{i}$, starting from a steady state. This shifts downward curve $\dot{\zeta}_{m, i}=0$ in Figure 1 and does not alter the $\dot{m}_{i}=0$ curve (see the steady state conditions (19) and (20)). In response, $\zeta_{m, i}$ jumps down on impact and rises gradually afterwards while $m_{i}$ gradually declines, until they reach a new steady state. These dynamics imply that the firm's foreign market share rises on impact and gradually declines afterwards, yet it remains higher than the initial share along the entire path. ${ }^{17}$ The initial rise in the foreign market share is driven by an increase in the number of exported products as a result of expansion of the product span, while the subsequent gradual decline is driven by a decrease in the product span of foreign subsidiaries.

${ }^{15}$ Recall that firm $i$ 's exports relative to subsidiary sales equal (see (11))

$$
\rho_{i}=\tau^{1-\sigma} \frac{n_{i}-m_{i}}{m_{i}}
$$

Therefore every large firm reduces this ratio on impact in response to an increase in $\tau$ and this ratio further declines as $m_{i}$ rises. If the foreign prices $p_{m, i}, i=1,2, \ldots, I$ were constant, this would imply that aggregate exports relative to subsidiary sales, $\rho$, decline (see footnote 9). But these prices decline on impact for all firms, as is evident from (13), and rise gradually afterwards. They therefore exert an independent effect on $\rho$. For this reason the impact on $\rho$ is ambiguous.

${ }^{16}$ In the presence of the productivity shifter $z_{m}$ the steady state condition (20) is replaced with

$$
z_{m} \phi_{m}\left[\varphi_{m}\left(1 / z_{m} \zeta_{m, i}\right)\right]=\theta m_{i}
$$

Since the left-hand side of this equation is rising in $z_{m}$, an increase in $z_{m}$ shifts rightward the $\dot{m}_{i}=0$ curve.

${ }^{17}$ This is seen from the fact that $\zeta_{m, i}$ remains below its initial value on the entire trajectory, including the new steady state. 


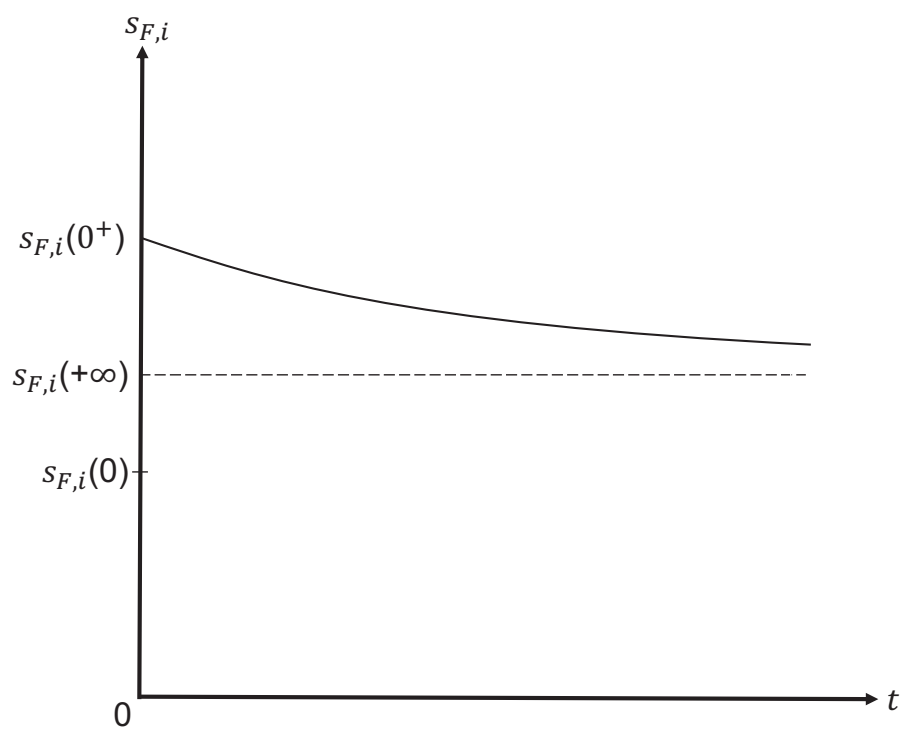

Figure 2: Dynamics of the foreign market share in response to a one-time increase in $n_{i}$

While the latter further increases the number of exported products, the fall in subsidiary sales dominates the expansion of exports in modifying the foreign market share.

This dynamic pattern is exhibited in Figure 2. The initial steady-state foreign market share is $s_{F, i}(0)$. It jumps on impact to $s_{F, i}\left(0^{+}\right)$and gradually declines afterwards to $s_{F, i}(+\infty)$. Moreover, the one-time rise in $n_{i}$ raises on impact the domestic market share that stays constant ever after. Since markups are rising in market shares, it follows that firm $i$ 's domestic markup rises on impact and remains at this higher level for the rest of time while the foreign markup rises on impact and gradually declines. Nevertheless, the foreign markup remains higher than its initial value at every point in time after the shock. The dynamics of the foreign product span imply that firm $i$ 's exports relative to subsidiary sales rise on impact and keep rising after the initial shock until the firm reaches its new steady state (see (11)). These findings are summarized in

Proposition 4. Suppose that $n_{i}$ is constant and MNE $i$ is in a steady state. Then a one-time increase in $n_{i}$ : (i) raises on impact $i$ 's domestic market share and markup and both remain constant afterwards; (ii) raises on impact i's foreign market share and markup, which gradually decline after that until they reach a new steady state, and both are higher at all times than they were in the initial steady state; (iii) gradually contracts the product span of the firm's foreign affiliates; and (iii) raises on impact $i$ 's exports relative to subsidiary sales and this ratio rises gradually afterwards until the firm reaches a new steady state.

Evidently, a one-time rise in $n_{i}$ sets in motion non-monotonic dynamics of the foreign market share and markup and monotonic dynamics of the foreign product span and exports relative to subsidiary sales. It also generates a one-time adjustment of the domestic market share and markup. The gradual decline in $m_{i}$ results from substitutability between the firm's aggregate product span and its foreign product span. An increase in $n_{i}$ reduces the marginal profits of foreign direct 
investment and thereby reduces investment in foreign subsidiaries. Combined with the natural attrition of $m_{i}$, the lower incentive to expand foreign manufacturing of varieties leads to a gradual decline in the foreign product span.

Next, consider an improvement in MNE $i$ 's labor productivity $1 / a_{i}$ (a decline in $a_{i}$ ). This costsaving change raises the marginal profitability of foreign direct investment for a given foreign market share. Yet it also raises the foreign market share, which reduces marginal profits from FDI. We show in the appendix that the former effect dominates if and only if ${ }^{18}$

$$
\left(\sigma-\delta s_{F, i}-1\right)^{2}\left[\sigma^{2}-\left(\delta s_{F, i}\right)^{2}\right]>(\sigma-1)\left(\delta s_{F, i}\right)^{2}
$$

When this condition is satisfied the $\dot{\zeta}_{m, i}=0$ curve in Figure 1 shifts upward. In the opposite case it shifts downward. In both cases, the $\dot{m}_{i}=0$ curve does not change. When the $\dot{\zeta}_{m, i}=0$ curve shifts upward $\zeta_{m, i}$ jumps up to the new equilibrium trajectory. Subsequently $\zeta_{m, i}$ declines and $m_{i}$ rises. It follows that the foreign market share rises on impact (see appendix) and keeps rising afterwards, the foreign markup rises on impact and keeps rising after that, and exports relative to subsidiary sales gradually decline. These adaptations continue until the firm reaches a new steady state. In the opposite case, when the inequality in (21) is reversed, the $\dot{\zeta}_{m, i}=0$ curve shifts downward and $\zeta_{m, i}$ jumps down to the new equilibrium trajectory. After that $\zeta_{m, i}$ gradually rises while $m_{i}$ gradually declines. The foreign market share rises on impact and gradually declines afterwards. As a result, the foreign markup rises on impact and gradually declines afterwards throughout. Finally, during the transition to the new steady state exports rise relative to subsidiary sales. This productivity improvement raises on impact the firm's market share and markup in the home country and they remain constant afterwards.

This analysis shows that a firm's response to an improvement in labor productivity depends on its initial market share. Condition (21) is satisfied when the foreign market share is small. Moreover, since the left-hand side of $(21)$ is declining in $s_{F, i}$, it is always satisfied when ${ }^{19}$

$$
(\varepsilon-1)^{2}\left[\sigma^{2}-(\sigma-\varepsilon)^{2}\right]>(\sigma-1)(\sigma-\varepsilon)^{2} .
$$

Clearly, the last inequality holds for $\sigma \rightarrow \varepsilon>1$ and it is violated for $\varepsilon \rightarrow 1$. That being the case, there exists an $s_{c}$ that satisfies

$$
\left(\sigma-\delta s_{c}-1\right)^{2}\left[\sigma^{2}-\left(\delta s_{c}\right)^{2}\right]=(\sigma-1)\left(\delta s_{c}\right)^{2}
$$

such that the $\dot{\zeta}_{m, i}=0$ curve shifts upward in response to a labor productivity improvement in firm $i$ when $s_{F, i}<\min \left\{s_{c}, 1\right\}$ and downward when $s_{F, i}>s_{c}$.

We summarize these findings in

\footnotetext{
${ }^{18}$ Marginal profits of FDI are $\left(1-\tau^{1-\sigma}\right) \Lambda_{i}\left(s_{F, i}\right)$. A fall in $a_{i}$ shifts down the function $\Lambda_{i}\left(s_{F, i}\right)$ and raises $s_{F, i}$. Since $\Lambda_{i}\left(s_{F, i}\right)$ is a decreasing function, the rise the market share reduces marginal profits of FDI. See appendix for details.

${ }^{19}$ This condition is obtained from the observation that (21) is least likely to be satisfied for $s_{F, i}=1$.
} 
Proposition 5. Suppose that $n_{i}$ is constant and MNE $i$ is in a steady state. Then an increase in labor productivity $1 / a_{i}$ has the following effects: (i) If $s_{F, i}<\min \left\{s_{c}, 1\right\}$, where $s_{c}$ is given in (22), it raises on impact the firm's foreign market share and markup and they keep rising subsequently until the firm reaches a new steady state. The firm's foreign product span rises gradually and exports relative to subsidiary sales decline gradually until the firm reaches a new steady state. (ii) If $s_{F, i}>s_{c}$, the firm's foreign market share and markup rise on impact and gradually decline afterwards while its foreign product span contracts gradually and exports relative to subsidiary sales expand gradually until the firm reaches a new steady state. (iii) The firm's foreign market share is always larger in the new steady state. (iv) The firm's home-country market share and markup rise on impact and remain constant after that.

An interesting implication of this proposition is that if large firms differ in labor productivity but have a common product span, i.e., $n_{i}=n_{j}$ for all $i, j=1,2, \ldots, I$, then in the steady sate more productive firms have larger market shares at home and abroad. In spite of that, if the spread in labor productivity is wide enough so that (21) is satisfied for some of the least productive firms and violated for some of the most productive firm, there will be a non-monotonic steady-state relation between labor productivity and product span of foreign subsidiaries. This relation forms an inverted-U shape, similar to the result in Helpman and Niswonger (2021) regarding the relationship between labor productivity and product span in a closed economy, for which they provide suggestive evidence.

Whenever there is an inverted-U-shaped relation between labor productivity and product span of foreign subsidiaries, it leads to a U-shaped relationship between labor productivity and exports relative to subsidiary sales. In other words, controlling for a firm's product span, $n_{i}$, exports relative to subsidiary sales first decline and later rise with labor productivity. ${ }^{20}$ Naturally, if (21) is satisfied for all large firms then exports relative to subsidiary sales are negatively correlated with labor productivity and if (21) is violated for all large firms the correlation is positive.

In this section we analyzed FDI dynamics, treating as exogenous the large firms' product spans. However, in many cases large firms can engage in research and development in order to expand their product spans. If this is the case, a firm's labor productivity shapes its long-run product span as well as the product span of its foreign subsidiaries. Note from Proposition 4 that the larger is a firm's product span the smaller its the long-run product span of its foreign affiliates. This association interacts with the above-discussed correlations in forming the relationship between labor productivity and the product span of foreign subsidiaries, when $n_{i}$ is endogenous. We examine these issues in the next section.

\section{Innovation and FDI}

In this section we endow large firms with an innovation technology, without changing other details of the model. A firm can use this technology to augment its product span, similar to Klette and

\footnotetext{
${ }^{20}$ We will see in the next section that this relation is modified when $n_{i}$ is endogenous.
} 
Kortum (2004). As a result, firm $i$ can invest in either expanding $n_{i}$ or $m_{i}$. An investment flow of $\iota_{n, i}$ per unit time expands $n_{i}$ by $\phi_{n}\left(\iota_{n, i}\right)$ units per unit time. The innovation function $\phi_{n}\left(\iota_{n, i}\right)$ is increasing, concave, $\phi_{n}(0)=0$ and it satisfies the Inada conditions $\lim _{\iota \rightarrow 0} \phi_{n}^{\prime}(\iota)=+\infty$ and $\lim _{\iota \rightarrow+\infty} \phi_{n}^{\prime}(\iota)=0$. Furthermore, $n_{i}$ depreciates at the rate $\theta$ per unit time, randomly hitting every available brand. For these reasons $n_{i}$ satisfies the differential equation

$$
\dot{n}_{i}=\phi_{n}\left(\iota_{n, i}\right)-\theta n_{i}, \text { for all } t \geq 0 .
$$

In this environment, firm $i$ solves an optimal control problem in which $m_{i}$ and $n_{i}$ are state variables while FDI, $\iota_{m, i}$, and investment in innovation, $\iota_{n, i}$, are control variables, facing the initial conditions $m_{i}(0)=m_{i}^{0}$ and $n_{i}(0)=n_{i}^{0}$. This problem is spelled out in the appendix. Compared to the optimal control problem from the previous section it has an additional state variable, $n_{i}$, and an additional co-state variable, $\zeta_{n, i}$, affiliated with the differential equation for $n_{i}$. The first-order conditions of this problem yield four differential equations,

$$
\begin{gathered}
\dot{\zeta}_{m, i}=(r+\theta) \zeta_{m, i}-\left(1-\tau^{1-\sigma}\right) \Lambda_{i}\left\{s_{i}\left[\left(n_{i}-m_{i}\right) \tau^{1-\sigma}+m_{i}\right]\right\}, \\
\dot{m}_{i}=\phi_{m}\left[\varphi_{m}\left(\zeta_{m, i}^{-1}\right)\right]-\theta m_{i}, \\
\dot{\zeta}_{n, i}=(r+\theta) \zeta_{n, i}-\Lambda_{i}\left[s_{i}\left(n_{i}\right)\right]-\tau^{1-\sigma} \Lambda_{i}\left\{s_{i}\left[\left(n_{i}-m_{i}\right) \tau^{1-\sigma}+m_{i}\right]\right\}, \\
\dot{n}_{i}=\phi_{n}\left[\varphi_{n}\left(\zeta_{n, i}^{-1}\right)\right]-\theta n_{i},
\end{gathered}
$$

and two transversality conditions

$$
\begin{aligned}
& \lim _{t \rightarrow \infty} e^{-r t} \zeta_{m, i}(t) m_{i}(t)=0, \\
& \lim _{t \rightarrow \infty} e^{-r t} \zeta_{n, i}(t) n_{i}(t)=0 .
\end{aligned}
$$

The first two differential equations are the same as (17) and (18); they describe the dynamics of the product span of foreign subsidiaries, $m_{i}$, and its co-state variable, $\zeta_{m, i}$. The third and fourth differential equations describe the dynamics of $n_{i}$ and its co-state variable $\zeta_{n, i}$. In the differential equation for $\zeta_{n, i}$ the marginal profitability of $n_{i}$ has two terms, one resulting from $n_{i}$ 's impact on profits in the domestic market, $\Lambda_{i}\left[s_{i}\left(n_{i}\right)\right]$, and one resulting from its impact on profits in the foreign market, $\tau^{1-\sigma} \Lambda_{i}\left[s_{i}\left(n_{F, i}\right)\right]$, where $n_{F, i}=\left(n_{i}-m_{i}\right) \tau^{1-\sigma}+m_{i}$ is the effective number of products the firm sells in the foreign country. In comparison, in the differential equation for $\zeta_{m, i}$ the marginal profitability of $m_{i}$ has only one term, $\left(1-\tau^{1-\sigma}\right) \Lambda_{i}\left[s_{i}\left(n_{F, i}\right)\right]$, that results from its impact on profits in the foreign market, because $m_{i}$ has no influence on profits in the domestic market.

The first transversality condition is the same as the transversality condition in the previous section while the second transversality condition applies to the dynamics of $n_{i}$. A trajectory that leads to a steady state satisfies both conditions.

We show in the appendix that this dynamic system satisfies local saddle-path stability around 
the steady state. That is, we show that the $4 \times 4$ matrix of the linearized system of the differential equations, evaluated at the steady state values of $m_{i}, n_{i}, \zeta_{m, i}$ and $\zeta_{n, i}$, has two positive and two negative characteristic roots. As a result, the four free coefficients of the general solution to this linear system of differential equations can be chosen to yield $m_{i}(0)=m_{i}^{0}$ and $n_{i}(0)=n_{i}^{0}$, on one hand, and initial values of $\zeta_{m, i}(0)$ and $\zeta_{n, i}(0)$ that place the system on a path that converges to the steady state, on the other.

In a steady state $\dot{\zeta}_{m, i}=\dot{\zeta}_{n, i}=\dot{m}_{i}=\dot{n}_{i}=0$. From $\dot{m}_{i}=0$ we can solve $\zeta_{m, i}$ as a function of $m_{i}$, $\zeta_{m, i}=\psi_{m, i}\left(m_{i}\right)$, while from $\dot{n}_{i}=0$ we can solve $\zeta_{n, i}$ as a function of $n_{i}, \zeta_{n, i}=\psi_{n, i}\left(n_{i}\right)$, where both functions are increasing in their arguments. Substituting these functions into $\dot{\zeta}_{m, i}=\dot{\zeta}_{n, i}=0$ yields

$$
\begin{gathered}
(r+\theta) \psi_{m, i}\left(m_{i}\right)-\left(1-\tau^{1-\sigma}\right) \Lambda_{i}\left\{s_{i}\left[\left(n_{i}-m_{i}\right) \tau^{1-\sigma}+m_{i}\right]\right\}=0, \\
(r+\theta) \psi_{n, i}\left(n_{i}\right)-\Lambda_{i}\left[s_{i}\left(n_{i}\right)\right]-\tau^{1-\sigma} \Lambda_{i}\left\{s_{i}\left[\left(n_{i}-m_{i}\right) \tau^{1-\sigma}+m_{i}\right]\right\}=0 .
\end{gathered}
$$

The first equation describes a relationship between $m_{i}$ and $n_{i}$ that secures FDI at a level that keeps $m_{i}$ constant and a discounted present value of marginal profits from FDI that motivates the firm to engage in this investment level. ${ }^{21}$ This relationship is depicted by the downward sloping $M M$ curve in Figure 3, in line with the result in Proposition 4(iii). Sliding down the $M M$ curve raises $m_{i}$ and reduces $n_{i}$, but also reduces $n_{F, i}$ - the effective number of products sold in $F$ - and the foreign market share. While the foreign market share rises in response to the expansion of the product span of foreign subsidiaries, the decline in the range of exported products has a larger negative effect on $n_{F, i}$. The decline of $n_{i}$ reduces the domestic market share and therefore the foreign and domestic market shares are positively correlated along the $M M$ curve.

The second equation describes a relationship between $m_{i}$ and $n_{i}$ that secures an R\&D level that keeps $n_{i}$ constant and a discounted present value of marginal profits from $\mathrm{R} \& \mathrm{D}$ that motivates the firm to engage in this level of investment. This relationship is depicted by the downward sloping $N N$ curve in Figure 3. The $M M$ curve is steeper at the intersection point of the two curves, as depicted in the figure (see appendix for a proof). Sliding up the $N N$ curve raises $n_{i}$ and reduces $m_{i}$, but also reduces $n_{F, i}$ and the foreign market share. While the foreign market share rises in response to the increase in the number of exported goods it declines in response to the contraction of the number of products manufactured by foreign subsidiaries and the latter effect dominates the shift in $n_{F, i}$. Since an increase in $n_{i}$ raises the domestic market share, it follows that the domestic and foreign market shares are negatively correlated along the $N N$ curve. The intersection point between the $M M$ and $N N$ curves at point $e$ describes the long-run equilibrium point.

In the previous section we analyzed the impact of a productivity improvement in FDI, treating as exogenous the product spans $n_{i}, i=1,2, \ldots, I$. We found that it raised the product span of foreign subsidiaries, their prices and markups, their foreign market shares and reduced every large firm's exports relative to subsidiary sales (see Proposition 3(iii)). To analyze the impact of this type of productivity improvement in the current setting, where the product span is endogenous, we turn to

\footnotetext{
${ }^{21}$ The discounting includes the interest rate, $r$, and the attrition rate, $\theta$.
} 


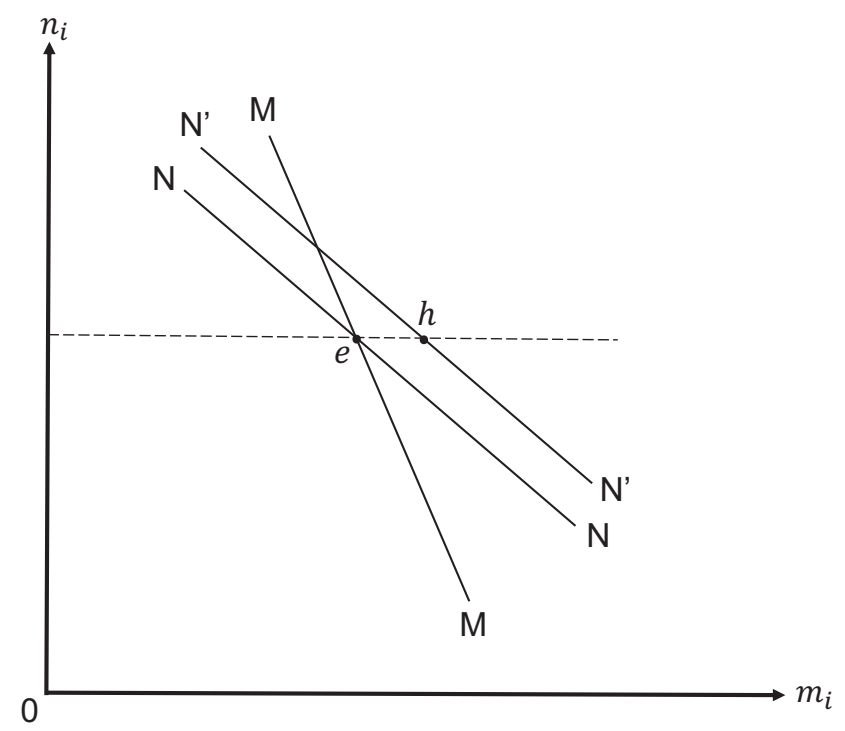

Figure 3: Steady state values of $m_{i}$ and $n_{i}$

Figure 3. A productivity improvement in FDI shifts the $M M$ curve rightward and does not modify the $N N$ curve. $^{22}$ This leads to a larger product span of foreign subsidiaries but a smaller overall span of the firm's products. That is, $n_{i}$ declines in the long run. This is another manifestation of the inherent substitutability between $m_{i}$ and $n_{i}$ in this environment. While in the previous section, when $n_{i}$ was constant, an improvement in the foreign investment technology had no impact on the domestic product spans, prices, markups or market shares, now this technical change induces firm $i$ to reduce its domestic price, markup and market share. In contrast, the market share rises in the foreign country, because sliding down the $N N$ curve reduces the domestic market share and raises the foreign market share. As a result, firm $i$ 's foreign subsidiaries charge a higher price and a higher markup, fewer products are exported and more products are produced in the foreign country. This leads to lower exports relative to subsidiary sales, in line with the proximity-concentration tradeoff theory of foreign direct investment.

Technical change that raises R\&D efficiency shifts upward the $N N$ curve, which leads to a larger product span, $n_{i}$, and fewer varieties manufactured by foreign subsidiaries, $m_{i}$. This raises the firm's price, markup and market share in the domestic economy. Along the $M M$ curve the foreign and domestic market shares are positively correlated. Therefore this technical improvement raises the foreign market shares, prices charged by foreign subsidiaries and the foreign markups. Moreover, since fewer products are produced by foreign subsidiaries and more products are exported, every large firm's exports rise relative to subsidiary sales. We summarize these findings in

Proposition 6. Suppose MNE $i$ is in a steady state. Then: (i) an improvement in the FDI technology leads to higher $m_{i}$ and lower $n_{i}$ in the new steady state, a higher market share in the foreign

\footnotetext{
${ }^{22}$ As in the previous section, we replace the function $\phi_{m}(\iota)$ with $z_{m} \phi_{m}(\iota)$, where $z_{m}=1$ initially, and examine an increase in $z_{m}$.
} 
market and a lower market share at home, a higher price and markup in the foreign country and a lower price and markup at home, and smaller exports relative to subsidiary sales; (ii) an improvement in the RESD technology leads to lower $m_{i}$ and higher $n_{i}$ in the new steady state, higher market shares in both countries, higher prices and markups in both countries, and larger exports relative to subsidiary sales.

Interestingly, while technical improvements in the $R \& D$ technology generate positive correlations between a large firm's responses at home and abroad and they raise exports relative to subsidiary sales, technical improvements in the FDI technology generate negative correlations between the firm's responses at home and abroad and they reduce exports relative to subsidiary sales.

We next reexamine the impact of higher export $\operatorname{costs} \tau$. Proposition 3 shows that for a constant product span $n_{i}$ an increase in $\tau$ raises firm $i$ 's span of foreign subsidiaries and reduces exports relative to subsidiary sales. At the same time the firm makes no changes in the domestic market. Now, when product spans are endogenous, an increase in $\tau$ shifts rightward curve $M M$ in Figure 3. If curve $N N$ were to remain anchored at the original equilibrium point, this would imply that $m_{i}$ rises in the long run and $n_{i}$ declines. Yet $N N$ is unlikely to remain anchored at this point; it shifts down if and only if (see appendix)

$$
\eta_{\Lambda_{i}}\left(s_{F, i}\right) \eta_{s_{i}}\left(n_{F, i}\right) \frac{\left(n_{i}-m_{i}\right) \tau^{1-\sigma}}{\left(n_{i}-m_{i}\right) \tau^{1-\sigma}+m_{i}}<1,
$$

where $\eta_{\Lambda_{i}}\left(s_{F, i}\right)$ is the absolute value of the elasticity of $\Lambda_{i}(\cdot)$ evaluated at $s_{F, i}$ and $\eta_{s_{i}}\left(n_{F, i}\right)$ is the elasticity of $s_{i}(\cdot)$ evaluated at $n_{F, i}$. This condition is more likely to be satisfied when the foreign market share is small. ${ }^{23}$ When $N N$ shifts down the final outcome is higher $m_{i}$ and lower $n_{i}$. But even if $N N$ shifts up the final outcome may still be higher $m_{i}$ and lower $n_{i}$. When $m_{i}$ rises and $n_{i}$ declines the firm manufactures a wider span of products in foreign subsidiaries and exports fewer products from home. As a result, exports decline relative to subsidiary sales. At the same time the firm sells fewer products in the home market, where it reduces the price, markup and market share.

Recall from the previous section that an improvement in firm $i$ 's labor productivity, $1 / a_{i}$, raises the marginal value of investment in the product span of foreign subsidiaries, $\left(1-\tau^{1-\sigma}\right) \Lambda_{i}\left(s_{F, i}\right)$, if and only if the foreign market share is small enough, i.e., $s_{F, i}<\min \left\{s_{c}, 1\right\}$ (see Proposition $5)$. The same argument establishes that an improvement in firm $i$ 's labor productivity raises the marginal value of investment in product span $n_{i}, \Lambda_{i}\left(s_{i}\right)$, if and only if the home country market share is small enough, i.e., $s_{i}<\min \left\{s_{c}, 1\right\}$ (see appendix). When $\Lambda_{i}\left(s_{F, i}\right)$ increases in response to an improvement in the firm's labor productivity the $M M$ curve in Figure 3 shifts to the right while

\footnotetext{
${ }^{23}$ We show in the appendix that
}

$$
\begin{gathered}
\eta_{s_{i}}(n)=\frac{\left[\sigma-\delta s_{i}(n)-1\right]\left[\sigma-\delta s_{i}(n)\right]}{\left[\sigma-\delta s_{i}(n)-1\right]\left[\sigma-\delta s_{i}(n)\right]+(\sigma-1) \delta s_{i}(n)} \\
\eta_{\Lambda_{i}}(s)=\delta^{2} s^{2} \frac{2(\sigma-\delta s-1)(\sigma-\delta s)+\sigma(\sigma-1)}{(\sigma-\delta s-1)(\sigma-\delta s)\left[(\sigma-\delta s-1) \sigma+\delta^{2} s^{2}\right]} .
\end{gathered}
$$

Therefore $\eta_{s_{i}}\left(n_{F, i}\right) \epsilon(0,1)$ and the inequality is satisfied for $s_{F, i}$ small enough. 
the $N N$ curve shifts upward. In contrast, when $\Lambda_{i}\left(s_{i}\right)$ increases in response to an improvement in the firm's labor productivity the $M M$ curve does not change while the $N N$ curve shifts upward. It follows that when an improvement in labor productivity shifts upward both $\Lambda_{i}\left(s_{F, i}\right)$ and $\Lambda_{i}\left(s_{i}\right)$ the $M M$ curve shifts to the right while the $N N$ curve shifts upward.

Figure 3 shows the initial equilibrium point $e$, where the $N N$ and $M M$ curves intersect, and the upward shift in the $N N$ curve to $N^{\prime} N^{\prime}$ as a result of upward shifts in $\Lambda_{i}\left(s_{F, i}\right)$ and $\Lambda_{i}\left(s_{i}\right)$ in response to a rise in labor productivity. Since $s_{i}>s_{F, i}$, condition $s_{i}<\min \left\{s_{c}, 1\right\}$ is sufficient for $\Lambda_{i}\left(s_{F, i}\right)$ and $\Lambda_{i}\left(s_{i}\right)$ to increase in response to a decline in $a_{i}$. We now argue that the rightward shift of the $M M$ curve is to the left of point $h$. To see why, note from (25) that at point $h$ the marginal value $\Lambda_{i}\left(s_{F, i}\right)$ has to be lower than it was originally at $e$ (i.e., before the change in labor productivity), because $\Lambda_{i}\left(s_{i}\right)$ is higher. For this reason, the left-hand side of (24) is positive at $h$ and the rightward shift of $M M$ stops short of point $h$. Under these circumstances the new equilibrium point is above the horizontal line through $e$ and $h$ and for that reason product span $n_{i}$ is larger in the new equilibrium (see appendix for an analytical proof). It is also clear from the figure that the product span of foreign subsidiaries may rise or decline in response to firm $i$ 's improvement in labor productivity. A similar analysis shows that whenever $s_{F, i}>s_{C}$ in the initial equilibrium, and therefore $s_{i}>s_{c}$, an improvement in labor productivity induces firm $i$ to contract its product span in the long run, but the firm may expand or contract the product span of its foreign subsidiaries.

In spite of the ambiguity concerning the response of $m_{i}$ to changes in labor productivity, we show in the appendix that there is no ambiguity concerning the response of the effective number of products sold in the foreign county, $n_{F, i}$; it rises with labor productivity when $s_{i}<\min \left\{s_{c}, 1\right\}$ and declines with labor productivity when $s_{F, i}>s_{c}$. We summarize these findings in

Proposition 7. Suppose MNE $i$ is in a steady state. Then an improvement in its labor productivity $1 / a_{i}$ : (i) raises $n_{i}$ and $n_{F, i}$ in the long run when $s_{i}<\min \left\{s_{c}, 1\right\}$; and (ii) reduces $n_{i}$ and $n_{F, i}$ in the long run when $s_{F, i}>s_{C}$.

These results imply that in the cross section of firms the relationship between labor productivity and long-run product spans $n_{i}$ has an inverted-U shape whenever the smallest value of labor productivity secures a domestic market share smaller than $\min \left\{s_{c}, 1\right\}$ and the largest value secures a foreign market share larger than $s_{c}$. This is an extension to an open economy of a result from Helpman and Niswonger (2021) for which they provide suggestive evidence. ${ }^{24}$ Moreover, the proposition implies that in these circumstances an inverted- $U$ relationship exists between the effective number of products supplied to the foreign country, $n_{F, i}$, and labor productivity.

Improvements in firm $i$ 's labor productivity directly raise its market shares in both countries when the (effective) numbers of products sold in those countries do not change. Additionally, the firm's market share in a particular country is larger the larger is the (effective) number of products sold there. Therefore, as long as $s_{i}<\min \left\{s_{c}, 1\right\}$, higher labor productivity raises the firm's market share at home and abroad, because both the direct effect of labor productivity and its indirect

\footnotetext{
${ }^{24}$ Clearly, if $s_{c}>1$ there is no inverted-U relationship and more productive firms have larger product spans in the long run.
} 

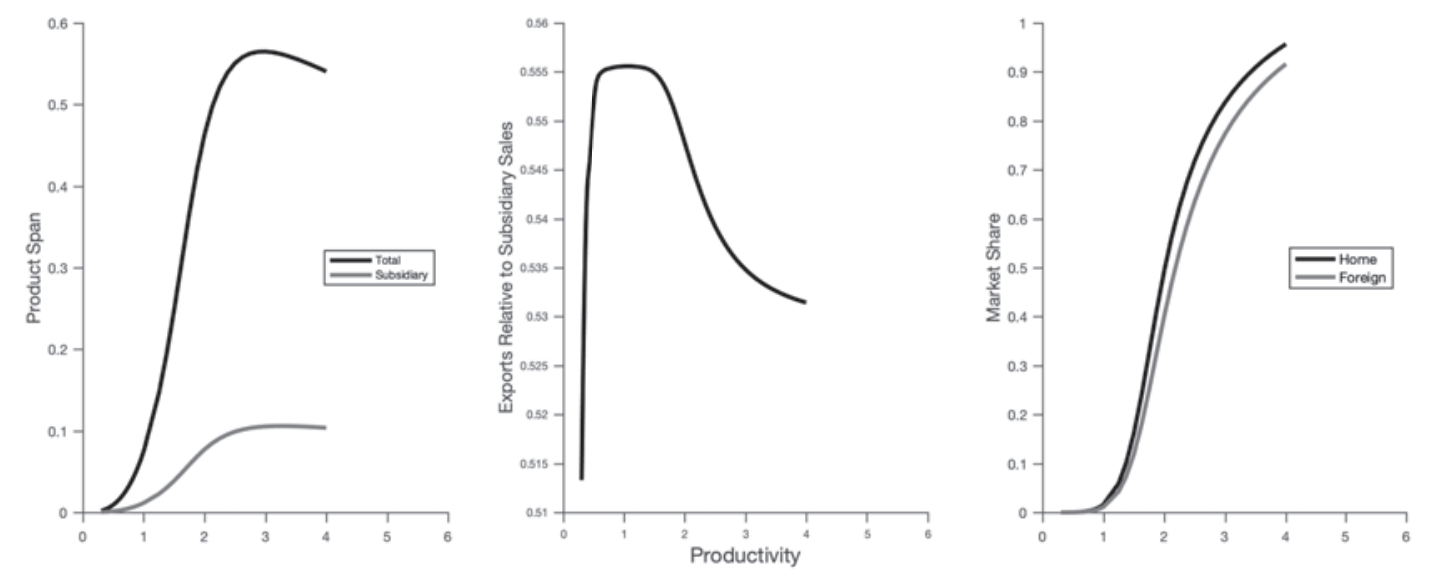

Figure 4: Steady-state relationships

effect (through the number of products) raise these market shares. In contrast, when $s_{F, i}>s_{c}$, the direct effect raises market shares at home and abroad while the indirect effect reduces them. We nevertheless show in the appendix that in this case the market share rises at home or abroad, and we find in our simulations that both market shares tend to rise with productivity. ${ }^{25}$

We illustrate in Figure 4 a set of steady-state relationships between market shares, product spans and exports relative to subsidiary sales. ${ }^{26}$ In this example market shares rise with labor productivity. At the same time, both the overall product span and the product span of foreign affiliates have an inverted-U shape, as suggested by the theory. Furthermore, in this example exports relative to subsidiary sales have an inverted- $U$ shape, with variation in a band smaller than five percentage points. The latter contrasts with the finding in the previous section, where $n_{i}$ was exogenous and constant, of a U-type relation between productivity and exports relative to subsidiary sales. The difference is caused by the endogeneity of $n_{i}$. When both the overall product span and the product span of foreign affiliates change in the same direction, the ratio $n_{i} / m_{i}$-which drives exports relative to subsidiary sales - may rise or decline. In the example, it produces the inverted-U shape.

\section{Summary}

We have developed a model of oligopolistic multinational enterprises that engage in foreign direct investment (FDI) and product innovation. FDI expands the range of products manufactured by foreign subsidiaries while R\&D contributes new varieties to a firm's product span. We show in Section 4.1 that in response to an increase in export costs, holding constant the number of a firm's products, an MNE reduces on impact the price charged by its foreign subsidiaries, the foreign markup, the foreign market share and exports relative to subsidiary sales. Furthermore, during the subsequent transition to a new steady state every oligopolistic firm gradually expands the number of

\footnotetext{
${ }^{25}$ In Helpman and Niswonger (2021) we show that in a closed economy the market share always rises.

${ }^{26}$ In this example $\sigma=4, \varepsilon=1.5, r=0.05, \theta=0.05, \tau=1.15, P=0.8, \phi_{m}(\iota)=0.75 \sqrt{\iota}, \phi_{n}(\iota)=0.1 \sqrt{\iota}$.
} 
products sold by its foreign affiliates, raises its foreign prices, markups and market share, and keeps reducing exports relative to subsidiary sales. The response of exports relative to subsidiary sales is consistent with the proximity-concentration tradeoff theory of MNEs, for which there is robust evidence. At the same time, the non-monotonic responses of prices, markups and market shares, predicted by our model, have not been tested empirically.

A reduction in FDI costs prompts monotonic gradual adjustments of foreign prices, markups, market shares and exports relative to subsidiary sales, led by expansion of the product spans of foreign affiliates of the MNEs. Foreign prices, markups and market shares rise during the transition while exports relative to subsidiary sales decline. So in this case too the response of exports relative to subsidiary sales is consistent with the proximity-concentration tradeoff theory of foreign direct investment. Interestingly, the home country prices, markups and market shares of the MNEs change neither in response to higher trade costs nor to lower FDI costs.

Home country prices, markups and market shares are, however, sensitive to the number of available products. A larger product span raises the domestic price, markup and market share of an MNE. But in addition, it impacts the firm's calculus in the foreign market. First, the firm raises on impact the foreign prices, markups and market share, which subsequently decline during the transition. Nevertheless, these variables remain higher at every point in time than they were in the initial equilibrium. Second, exports relative to subsidiary sales rise on impact and keep rising during the transition, led by a gradual contraction of the number of products available to the firm's foreign affiliates. The last result discloses an interdependence between an MNE's product span and the product span of its foreign affiliates: a larger product span reduces the marginal profitability of FDI, thereby inducing a contraction of the product span of its foreign subsidiaries. This property plays a key role in the joint dynamics of FDI and innovation, discussed in Section 5.

A final analysis in Section 4.1 addresses the role of labor productivity. Recall that varieties of the differentiated product are produced with labor only, and we allow labor productivity to vary across multi-product firms. We show that an improvement in a firm's labor productivity raises its markups and market share in the home country, but the impact in the foreign country depends on the initial foreign market share. An MNE that has a foreign market share below a certain threshold responds by instantly raising its foreign markups and market share, and it keeps raising them subsequently together with the product span of foreign affiliates until it reaches a new steady state. Exports relative to subsidiary sales decline during this transition. Alternatively, an MNE that has a foreign market share above the threshold also responds by instantly raising the foreign markups and market share. But unlike the firm with a small market share, its foreign markups and market share subsequently decline during the transition, although they remain higher throughout than they were in the initial equilibrium. Moreover, the firm gradually reduces the number of products available to its foreign subsidiaries and raises exports relative to subsidiary sales.

These results imply that if the MNEs differ only in labor productivity and the distribution of labor productivity has a large support, then the steady state relationship between product spans of foreign affiliates and labor productivity will exhibit and inverted-U shape, while the relationship 
between exports relative to subsidiary sales and labor productivity will exhibit a U shape. These are interesting findings that can be tested with suitable data. ${ }^{27}$ There is, however, a paucity of data sets with detailed information about products that MNEs manufacture at home and abroad, which are needed for this type of test. Yet there has been progress on this front, and Head and Mayer (2019) provide a good example of this progress for the car industry.

In Section 5 we study the joint determination of a firm's product span and the product span of its foreign affiliates, by allowing MNEs to invest in product innovation along the lines of Klette and Kortum (2004). We characterize the solution to a multi-product firm's optimal control problem in which an MNE's product span and the product span of its foreign affiliates are state variables while $R \& D$ and FDI are control variables. We show that the solution path of this problem is saddle-path stable around the steady state. Now a reduction in FDI costs raises the product span of foreign affiliates in the long run and reduces the MNE's product span. As a result, it raises the foreign prices, markups and market share and reduces the domestic price, markup and market share, and it reduces exports relative to subsidiary sales. In contrast, an improvement in the $R \& D$ technology reduces the foreign product span in the long run and increases the MNE's product span. This leads to higher prices, markups and market shares in both countries and to larger exports relative to subsidiary sales. Now the cross-sectional relationship between firm-level product spans and labor productivity can have an inverted-U shape, and so can the relationship between product spans of foreign subsidiaries and labor productivity and the relationship between exports relative to subsidiary sales and labor productivity.

Our model can be extended to include multiple sectors and multiple countries as well as simple forms of comparative advantage. More challenging, however, is to include platform FDI and timevarying stochastic shocks. These remain topics for future research.

\footnotetext{
${ }^{27}$ The former result is reminiscent of the closed-economy finding in Helpman and Niswonger (2021), who show that the relationship between product span and labor productivity has an inverted-U shape. They provide suggestive evidence for this relationship. Similar economic forces shape these results. Needless to say, the U-shaped relationship between exports relative to subsidiary sales and labor productivity is unique to the open economy.
} 


\section{References}

Antras, P. and Yeaple, S. R. (2014) Multinational Firms and the Structure of International Trade, in Handbook of International Economics (Eds.) G. Gopinath, E. Helpman and K. Rogoff, North Holland, Amsterdam, The Netherlands, vol. 4, pp. 55-130.

Arkolakis, C., Ramondo, N., Rodriguez-Clare, A. and Yeaple, S. (2018) Innovation and Production in the Global Economy, The American Economic Review, 108, 2128-2173.

Cao, D., Hyatt, H., Mukoyama, T. and Sager, E. (2019) Firm growth through new establishments, SSRN Electronic Journal.

Garetto, S., Oldenski, L. and Ramondo, N. (2021) Multinational expansion in time and space, Working paper.

Gumpert, A., Li, H., Moxnes, A., Ramondo, N. and Tintelnot, F. (2020) The life-cycle dynamics of exporters and multinational firms, Journal of International Economics, 126, 1-37.

Head, K. and Mayer, T. (2019) Misfits in the car industry: Offshore assembly decisions at the variety level, Journal of the Japanese and International Economies, 57, 90-105.

Helpman, E., Melitz, M. J. and Yeaple, S. R. (2004) Export versus FDI with Heterogeneous Firms, The American Economic Review, 94, 300-316.

Helpman, E. and Niswonger, B. (2021) Dynamics of Markups, Concentration and Product Span, American Economic Journal: Macroeconomics, forthcoming.

Kehrig, M. and Vincent, N. (2019) Good dispersion, bad dispersion, NBER Working Paper Series 25923, National Bureau of Economic Research, Inc.

Klette, T. J. and Kortum, S. (2004) Innovating firms and aggregate innovation, Journal of Political Economy, 112, 986-1018.

Parenti, M. (2018) Large and small firms in a global market: David vs. goliath, The Journal of International Economics, 110, 103-118.

Shimomura, K.-I. and Thisse, J.-F. (2012) Competition among the big and the small, The RAND Journal of Economics, 43, 329-347. 


\section{APPENDIX}

\section{A Instantaneous Equilibrium}

As described in the main text, large multi-product firms recognize the impact of their pricing policy on the price indexes $P_{F}$ and $P_{H}$. For this reason firm $i$, which seeks to maximize profits, solves the following problem:

$$
\max _{p_{i}, p_{e, i}, p_{m, i}} n_{i} P_{H}^{\delta} p_{i}^{-\sigma}\left(p_{i}-a_{i}\right)+\left(n_{i}-m_{i}\right) P_{F}^{\delta} p_{e, i}^{-\sigma}\left(p_{e, i}-\tau a_{i}\right)+m_{i} P_{F}^{\delta} p_{m, i}^{-\sigma}\left(p_{m, i}-a_{i}\right)
$$

subject to (4)-(5). The first-order conditions can be expressed as

$$
\begin{gathered}
\delta \frac{n_{i} p_{i}^{1-\sigma}}{P_{H}^{1-\sigma}}=\left(\sigma-\frac{p_{i}}{p_{i}-a_{i}}\right), \\
\delta \frac{\left(n_{i}-m_{i}\right) p_{e, i}^{1-\sigma}}{P_{F}^{1-\sigma}}=\frac{\left(n_{i}-m_{i}\right) p_{e, i}^{-\sigma}\left(p_{e, i}-\tau a_{i}\right)}{\left(n_{i}-m_{i}\right) p_{e, i}^{-\sigma}\left(p_{e, i}-\tau a_{i}\right)+m_{i} p_{m, i}^{-\sigma}\left(p_{m, i}-a_{i}\right)}\left(\sigma-\frac{p_{e, i}}{p_{e, i}-\tau a_{i}}\right), \\
\delta \frac{m_{i} p_{m, i}^{1-\sigma}}{P_{F}^{1-\sigma}}=\frac{m_{i} p_{m, i}^{-\sigma}\left(p_{m, i}-a_{i}\right)}{\left(n_{i}-m_{i}\right) p_{e, i}^{-\sigma}\left(p_{e, i}-\tau a_{i}\right)+m_{i} p_{m, i}^{-\sigma}\left(p_{m, i}-a_{i}\right)}\left(\sigma-\frac{p_{m, i}}{p_{m, i}-a_{i}}\right) .
\end{gathered}
$$

These equations imply $p_{e, i}=\tau p_{m, i}$. Using this result and adding up these equations yields (6), (7) and (8), where the relevant shares are defined in equations (9) and (10).

\section{B Properties of Shares and Prices}

Recall that $p_{e, i}=\tau p_{m, i}$. This allows us to rewrite equation (10) as

$$
s_{F, i}=\frac{\left[\left(n_{i}-m_{i}\right) \tau^{1-\sigma}+m_{i}\right] p_{m, i}^{1-\sigma}}{P_{F}^{1-\sigma}} .
$$

Noting that $p_{m, i}$ is solely a function of the share as seen in equation (8), we can see that $s_{F, i}$ and $p_{m, i}$ share the same relationship as $s_{i}$ and $p_{i}$. The only difference is that the effective number of products is given by $n_{F, i}:=\left(n_{i}-m_{i}\right) \tau^{1-\sigma}+m_{i}$ rather than by $n_{i}$. This allows us to write the foreign share as

$$
s_{F, i}=s_{i}\left(n_{F, i}\right)=s_{i}\left[\left(n_{i}-m_{i}\right) \tau^{1-\sigma}+m_{i}\right],
$$

where the function $s_{i}(n)$ is given by the joint solution to equations (9) and (6). Furthermore, this implies that because the price is simply a function of the share we have the analogous relationship for prices. That is

$$
p_{m, i}=p_{i}\left(n_{F, i}\right)=p_{i}\left[\left(n_{i}-m_{i}\right) \tau^{1-\sigma}+m_{i}\right] .
$$


We next use equations (6), (8), (9), and (10) to calculate the response of $p_{i}$ and $p_{m, i}$ to changes in the number of product lines, $n_{i}$, changes in marginal cost, $a_{i}$, changes in the product span of foreign subsidiaries, $m_{i}$, and changes in $\tau$ and the price index $P$. Denoting by a hat the proportional rate of change of a variable, i.e., $\hat{x}=d x / x$, differentiating these equations yields the solutions:

$$
\begin{gathered}
\hat{p}_{i}=\frac{\beta_{i}}{1+(\sigma-1) \beta_{i}} \hat{n}_{i}+\frac{1}{1+(\sigma-1) \beta_{i}} \hat{a}_{i}+\frac{(\sigma-1) \beta_{i}}{1+(\sigma-1) \beta_{i}} \hat{P}, \\
\hat{p}_{m, i}=\frac{\beta_{F, i}}{1+(\sigma-1) \beta_{F, i}} \frac{n_{i} \tau^{1-\sigma}}{\left(n_{i}-m_{i}\right) \tau^{1-\sigma}+m_{i}} \hat{n}_{i}+\frac{1}{1+(\sigma-1) \beta_{F, i}} \hat{a}_{i} \\
\quad+\frac{\beta_{F, i}}{1+(\sigma-1) \beta_{F, i}} \frac{\left(1-\tau^{1-\sigma}\right) m_{i}}{\left(n_{i}-m_{i}\right) \tau^{1-\sigma}+m_{i}} \hat{m}_{i}, \\
-\frac{\beta_{F, i}(\sigma-1)}{1+(\sigma-1) \beta_{F, i}} \frac{\left(n_{i}-m_{i}\right) \tau^{1-\sigma}}{\left(n_{i}-m_{i}\right) \tau^{1-\sigma}+m_{i}} \hat{\tau}+\frac{\beta_{F, i}(\sigma-1)}{1+(\sigma-1) \beta_{F, i}} \hat{P},
\end{gathered}
$$

where:

$$
\begin{gathered}
\beta_{i}=\frac{\delta s_{i}}{\left(\sigma-\delta s_{i}-1\right)\left(\sigma-\delta s_{i}\right)}>0, \\
\beta_{F, i}=\frac{\delta s_{F, i}}{\left(\sigma-\delta s_{F, i}-1\right)\left(\sigma-\delta s_{F, i}\right)}>0 .
\end{gathered}
$$

\section{Comparative Dynamics of FDI}

First, we derive the expression shown in equation (17). We begin from the first order condition expressed in the following form:

$$
-\frac{\partial \mathcal{H}}{\partial m_{i}}=-\frac{\partial \pi_{F, i}}{\partial m_{i}}+\zeta_{m, i} \theta=\dot{\zeta}_{m, i}-r \zeta_{m, i}
$$

We proceed by evaluating the marginal profits from increasing the span of foreign subsidiaries: $\frac{\partial \pi_{F, i}}{\partial m_{i}}$. By substituting in equation (16), this term becomes:

$$
\frac{\partial \pi_{F, i}}{\partial m_{i}}=\frac{\partial P^{\delta}\left[\left(n_{i}-m_{i}\right) \tau^{1-\sigma}+m_{i}\right] p_{m, i}\left(n_{i}, m_{i}\right)^{-\sigma}\left[p_{m, i}\left(n_{i}, m_{i}\right)-a_{i}\right]-\iota_{m, i}}{\partial m_{i}} .
$$

Evaluating this derivative with respect to $m_{i}$ results in

$$
\begin{aligned}
\frac{\partial \pi_{F, i}}{\partial m_{i}}= & P^{\delta} p_{m, i}^{-\sigma}\left[1-\tau^{1-\sigma}\right]\left(p_{i}-a_{i}\right) \\
& +P^{\delta} p_{m, i}^{-\sigma}\left[\left(n_{i}-m_{i}\right) \tau^{1-\sigma}+m_{i}\right]\left[(1-\sigma)+\sigma a_{i} p_{m, i}^{-1}\right] \frac{\partial p_{m, i}}{\partial m_{i}}
\end{aligned}
$$


From equation (27) we know that the elasiticity of foreign subsidiary price with respect to the foreign subsidiary product span is given by

$$
\frac{\partial p_{m, i}}{\partial m_{i}} \frac{m_{i}}{p_{m, i}}=\frac{\beta_{F, i}}{1+(\sigma-1) \beta_{F, i}} \frac{\left(1-\tau^{1-\sigma}\right) m_{i}}{\left(n_{i}-m_{i}\right) \tau^{1-\sigma}+m_{i}} .
$$

Subsituting this into equation (30) yields

$$
\begin{aligned}
\frac{1}{\left(1-\tau^{1-\sigma}\right)} \frac{\partial \pi_{F, i}}{\partial m_{i}}= & P^{\delta} p_{m, i}^{-\sigma}\left(p_{i}-a_{i}\right) \\
& +P^{\delta} p_{m, i}^{1-\sigma}\left[(1-\sigma)+\sigma a_{i} p_{m, i}^{-1}\right] \frac{\beta_{F, i}}{1+(\sigma-1) \beta_{F, i}}
\end{aligned}
$$

Substituting in equation (29) and simplifying returns the desired result:

$$
\frac{\partial \pi_{F, i}}{\partial m_{i}}=\left(1-\tau^{1-\sigma}\right) \Lambda_{i}\left[s_{F, i}\left(n_{i}, m_{i}\right)\right]
$$

where

$$
\Lambda_{i}(s)=\left(\frac{\sigma-\delta s}{\sigma-\delta s-1}\right)^{-\sigma} \frac{\sigma a_{i}^{1-\sigma} P^{\delta}}{\sigma(\sigma-\delta s-1)+(\delta s)^{2}} .
$$

In order to understand how parameter changes affect firm dynamics of foreign direct investment, it is sufficient to understand how they affect the steady state equations. A change in labor productivity of firm $i, 1 / a_{i}$, affects the steady state equation (19) but not equation (20). The effect of improved labor productivity on the firm's dynamics arises from the increased profitability of FDI. As discussed in the main body of the paper, there is a direct positive effect because each product produced by a subsidiary becomes more profitable, but there is also an indirect negative effect coming from the increase in the firm's market share. To see which of these dominates, it is sufficient to evaluate how the marginal profitability of expanding product span is affected by a change in productivity, i.e., $\frac{\partial \Lambda_{i}(s)}{\partial a_{i}} \frac{a_{i}}{\Lambda_{i}(s)}$. Totally differentiating (31) yields

$$
\hat{\Lambda}_{i}=-(\sigma-1) \hat{a}_{i}+\delta \hat{P}-\frac{\sigma \delta s}{(\sigma-\delta s-1)(\sigma-\delta s)} \hat{s}+\frac{\delta s(\sigma-2 \delta s)}{(\sigma-\delta s-1) \sigma+\delta^{2} s^{2}} \hat{s} .
$$

After collecting terms, we have

$$
\hat{\Lambda}_{i}=-(\sigma-1) \hat{a}_{i}+\delta \hat{P}-\delta^{2} s^{2} \frac{2(\sigma-\delta s-1)(\sigma-\delta s)+\sigma(\sigma-1)}{(\sigma-\delta s)(\sigma-\delta s-1)\left[(\sigma-\delta s-1) \sigma+(s \delta)^{2}\right]} \hat{s},
$$

which also proves that $\Lambda_{i}(s)$ is a decreasing function of $s$. Next we can calculate the relationship between $a_{i}$ and $s$, following the same derivation as for equation (26), to obtain 


$$
\hat{s}=-\frac{\sigma-1}{1+(\sigma-1) \beta} \hat{a}_{i} .
$$

Combining equations (32) and (34) yields

$$
\frac{\partial \Lambda_{i}(s)}{\partial a_{i}} \frac{a_{i}}{\Lambda_{i}(s)}=\frac{(\sigma-1)(\delta s)^{2}-(\sigma-\delta s-1)^{2}\left[\sigma^{2}-(\delta s)^{2}\right]}{(\sigma-\delta s-1)(\sigma-\delta s)\left[(\sigma-\delta s-1) \sigma+\delta^{2} s^{2}\right]^{2}}(\sigma-1) .
$$

When $(\sigma-1)\left(\delta s_{F, i}\right)^{2}-\left(\sigma-\delta s_{F, i}-1\right)^{2}\left[\sigma^{2}-\left(\delta s_{F, i}\right)^{2}\right]<0$, an increase in labor productivity (decrease in $a_{i}$ ) shifts upward the $\dot{\zeta}_{m, i}=0$, curve leading to higher $m_{i}$ in the long run. When this value is positive, an increase in labor productivity has an opposite effect on $m_{i}$.

\section{Full Dynamic Problem}

As described in the main text, firm $i$ solves an optimal control problem in which $m_{i}$ and $n_{i}$ are state variables while FDI, $\iota_{m, i}$, and investment in innovation, $\iota_{n, i}$, are control variables, facing the initial conditions $m_{i}(0)=m_{i}^{0}$ and $n_{i}(0)=n_{i}^{0}$. The two governing equations for the evolution of product span of foreign subsidiaries and the firm's product span are given by equations (15) and (23), respectively, reproduced below:

$$
\begin{gathered}
\dot{m}_{i}=\phi_{m}\left(\iota_{m, i}\right)-\theta m_{i}, \text { for all } t \geq 0, \\
\dot{n}_{i}=\phi_{n}\left(\iota_{n, i}\right)-\theta n_{i}, \text { for all } t \geq 0 .
\end{gathered}
$$

At every point in time the firms play a three stage game. In the first stage multi-product firms invest in innovation and in foreign subsidiaries. Namely, they choose $\iota_{n, i}$ and $\iota_{m, i}$. In the second stage single-product firms enter and they live only one instant of time. For this reason, they make profits only in this single instant. In the third stage all firms choose prices, in the manner described in Section 3. Under the circumstances in a subgame perfect equilibrium of the first stage game the price index $P$ is expected to be determined by the free entry condition (12), and it remains constant as long as the cost of entry and the cost of production of the single-product firms do no change. It follows that the profit flow of large firm $i$ is: ${ }^{28}$

$$
\begin{aligned}
\pi_{i}\left(\iota_{n, i}, \iota_{m, i}, n_{i}, m_{i}\right): & =P^{\delta} n_{i} p_{i}\left(n_{i}\right)^{-\sigma}\left[p_{i}\left(n_{i}\right)-a_{i}\right] \\
& +P^{\delta} n_{i} p_{i}\left(n_{i}\right)^{-\sigma}\left[p_{i}\left(n_{i}\right)-a_{i}\right] \\
& +P^{\delta}\left[\left(n_{i}-m_{i}\right) \tau^{1-\sigma}+m_{i}\right] p_{m, i}\left(n_{i}, m_{i}\right)^{-\sigma}\left[p_{m, i}\left(n_{i}, m_{i}\right)-a_{i}\right]-\iota_{n, i}-\iota_{m, i}, \\
& \text { for all } t \geq 0,
\end{aligned}
$$

$$
p_{m, i}\left(n_{i}, m_{i}\right):=p_{i}\left[\left(n_{i}-m_{i}\right) \tau^{1-\sigma}+m_{i}\right],
$$

\footnotetext{
${ }^{28}$ Recall that the export price of a variety not produced in $F$ is $p_{e, i}=\tau p_{m, i}$.
} 
where $P$ is the same at every $t$ while $\pi_{i}, n_{i}, m_{i}, p_{i}, p_{m, i}, \iota_{n, i}$ and $\iota_{m, i}$ vary over time. Moreover, $p_{i}$ is given by (6) and $p_{m, i}$ is given by (8). In this economy the state vector is $\{\boldsymbol{n}, \boldsymbol{m}\}=$ $\left\{\left(n_{1}, n_{2}, \ldots, n_{I}\right),\left(m_{1}, m_{2}, \ldots, m_{I}\right)\right\}$, a function of time $t$, and the prices $p_{i}$ and $p_{m, i}$ vary over time as functions of $\boldsymbol{n}, \boldsymbol{m}$. Note, however, from (6) and (8) that as long as all the parameters remain constant (and therefore $P_{H}=P_{F}=P$ remain constant as well) $p_{i}$ and $p_{m, i}$ depend only on the elements $\left\{n_{i}, m_{i}\right\}$ of $\{\boldsymbol{n}, \boldsymbol{m}\}$ on the dynamic path.

We now use (6), (8), (9) and (10) to obtain the elasticities of the functions $p_{i}\left(n_{i}\right), s_{i}\left(n_{i}\right)$, $p_{m, i}\left(n_{i}, m_{i}\right):=p_{i}\left[\left(n_{i}-m_{i}\right) \tau^{1-\sigma}+m_{i}\right]$ and $s_{F, i}\left(n_{i}, m_{i}\right):=s_{i}\left[\left(n_{i}-m_{i}\right) \tau^{1-\sigma}+m_{i}\right]:$

$$
\begin{gathered}
\frac{\partial p_{i}}{\partial n_{i}} \frac{n_{i}}{p_{i}}=\frac{\beta_{i}}{1+(\sigma-1) \beta_{i}}, \\
\frac{\partial s_{i}}{\partial n_{i}} \frac{n_{i}}{s_{i}}=\frac{1}{1+(\sigma-1) \beta_{i}}, \\
\frac{\partial p_{m, i}}{\partial n_{i}} \frac{n_{i}}{p_{m, i}}=\frac{\beta_{F, i}}{1+(\sigma-1) \beta_{F, i}} \frac{n_{i} \tau^{1-\sigma}}{\left(n_{i}-m_{i}\right) \tau^{1-\sigma}+m_{i}}, \\
\frac{\partial s_{F, i}}{\partial n_{i}} \frac{n_{i}}{s_{F, i}}=\frac{n_{i} \tau^{1-\sigma}}{1+(\sigma-1) \beta_{F, i}} \frac{\beta_{F, i}}{\left(n_{i}-m_{i}\right) \tau^{1-\sigma}+m_{i}}, \\
\frac{\partial p_{m, i}}{\partial m_{i}} \frac{m_{i}}{p_{m, i}}=\frac{\left(1-\tau^{1-\sigma}\right) m_{i}}{1+(\sigma-1) \beta_{F, i}} \frac{1}{\left(n_{i}-m_{i}\right) \tau^{1-\sigma}+m_{i}}, \\
\frac{\partial s_{F, i}}{\partial m_{i}} \frac{m_{i}}{s_{F, i}}=\frac{\left(1-\tau^{1-\sigma}\right) m_{i}}{1+(\sigma-1) \beta_{F, i}} \frac{\left(n_{i}-m_{i}\right) \tau^{1-\sigma}+m_{i}}{1+(2)}
\end{gathered}
$$

where $\beta_{i}$ and $\beta_{F, i}$ are defined in equations (28) and (29). Note that $\beta_{F, i}$ is increasing in $s_{F, i}$ and $s_{F, i}$ is increasing in $n_{i}$; therefore $\beta_{F, i}$ is increasing in $n_{i}$. The analogous statements are true for $\beta_{i}$, $s_{i}$ and $n_{i}$. As a result, the elasticity of the domestic price function is larger the larger is $s_{i}$ while the elasticity of the domestic market share function is smaller the larger is $s_{i}$, and similarly for the foreign price elasticity and foreign market share.

Next assume that the interest rate is constant and equal to $r$. This interest rate can be derived from the assumption that individuals discount future utility flows (1) with a constant rate $r$, so that they maximize the discounted present value of utility $\int_{0}^{\infty} e^{-r t} u(t) d t$. Under these circumstances firm $i$ maximizes the discounted present value of its profits net of investment costs. It therefore solves the following optimal control problem:

$$
\max _{\left\{\iota_{n, i}(t), \iota_{m, i}(t), n_{i}(t), m_{i}(t)\right\}_{t \geq 0}} \int_{0}^{\infty} e^{-r t} \pi_{i}\left[\iota_{n, i}(t), \iota_{m, i}(t), n_{i}(t), m_{i}(t)\right] d t
$$

subject to (37), (36), (38), $n_{i}(0)=n_{i}^{0}, m_{i}(0)=m_{i}^{0}$, and two transversality conditions to be described below. In this problem $\iota_{n, i}(t)$ and $\iota_{m, i}(t)$ are control variables while $n_{i}(t)$ and $m_{i}(t)$ are state variables. 
The current-value Hamiltonian of this problem is:

$$
\begin{aligned}
\mathcal{H}\left(\iota_{n, i}, \iota_{m, i}, n_{i}, m_{i}, \zeta_{n, i}, \zeta_{m, i}\right) & =\pi_{i}\left(\iota_{n, i}, \iota_{m, i}, n_{i}, m_{i}\right) \\
& +\zeta_{n, i}\left[\phi_{n}\left(\iota_{n, i}\right)-\theta n_{i}\right]+\zeta_{m, i}\left[\phi_{m}\left(\iota_{m, i}\right)-\theta m_{i}\right]-\iota_{n, i}-\iota_{m, i}
\end{aligned}
$$

where $\pi_{i}\left(\iota_{n, i}, \iota_{m, i}, n_{i}, m_{i}\right)$ is given in (38), $\zeta_{n, i}$ is the co-state variable of constraint (37) and $\zeta_{m, i}$ is the co-state variable of (36). These co-state variables vary over time. The first-order conditions of this optimal control problem are:

$$
\begin{gathered}
\frac{\partial \mathcal{H}}{\partial \iota_{n, i}}=-1+\zeta_{n, i} \phi_{n}^{\prime}\left(\iota_{n, i}\right)=0 \\
\frac{\partial \mathcal{H}}{\partial \iota_{m, i}}=-1+\zeta_{m, i} \phi_{m}^{\prime}\left(\iota_{m, i}\right)=0 \\
-\frac{\partial \mathcal{H}}{\partial n_{i}}=-\frac{\partial \pi_{i}\left(\iota_{n, i}, \iota_{m, i}, n_{i}, m_{i}\right)}{\partial n_{i}}+\theta \zeta_{n, i}=\dot{\zeta}_{n, i}-r \zeta_{n, i} \\
-\frac{\partial \mathcal{H}}{\partial m_{i}}=-\frac{\partial \pi_{i}\left(\iota_{n, i}, \iota_{m, i}, n_{i}, m_{i}\right)}{\partial m_{i}}+\zeta_{m, i} \theta=\dot{\zeta}_{m, i}-r \zeta_{m, i}
\end{gathered}
$$

and the transversality conditions are

$$
\begin{aligned}
& \lim _{t \rightarrow \infty} e^{-r t} \zeta_{n, i}(t) n_{i}(t)=0 . \\
& \lim _{t \rightarrow \infty} e^{-r t} \zeta_{m, i}(t) m_{i}(t)=0 .
\end{aligned}
$$

In addition, the optimal path of $\left(\iota_{n, i}, \iota_{m, i}, n_{i}, m_{i}\right)$ has to satisfy the differential equations (37) and (36), starting at $n_{i}^{0}$ and $m_{i}^{0}$.

Now note that

$$
\frac{\partial \pi_{i}}{\partial n_{i}}=\frac{\partial P^{\delta}\left\{n_{i} p_{i}\left(n_{i}\right)^{-\sigma}\left[p_{i}\left(n_{i}\right)-a_{i}\right]+\left[\left(n_{i}-m_{i}\right) \tau^{1-\sigma}+m_{i}\right] p_{m, i}\left(n_{i}, m_{i}\right)^{-\sigma}\left(p_{m, i}\left(n_{i}, m_{i}\right)-a_{i}\right)\right\}}{\partial n_{i}} .
$$

We can evaluate the marginal profitability of increased product span separately for the home and foreign markets. Consider first the marginal productivity in the home market:

$$
\frac{\partial P^{\delta} n_{i} p_{i}\left(n_{i}\right)^{-\sigma}\left[p_{i}\left(n_{i}\right)-a_{i}\right]}{\partial n_{i}}=P^{\delta} p_{i}^{-\sigma}\left[\left(p_{i}-a_{i}\right)+p_{i}\left[(1-\sigma)+\sigma a_{i} p_{i}^{-1}\right] \frac{\partial p_{i}}{\partial n_{i}} \frac{n_{i}}{p_{i}}\right] .
$$

Substituting in equation (39) and (6), we get that 


$$
\begin{aligned}
\frac{\partial P^{\delta} n_{i} p_{i}\left(n_{i}\right)^{-\sigma}\left(p_{i}\left(n_{i}\right)-a_{i}\right)}{\partial n_{i}} & =P^{\delta}\left(\frac{\sigma-\delta s_{i}}{\sigma-\delta s_{i}-1}\right)^{-\sigma} a_{i}^{1-\sigma}\left[\frac{1}{\sigma-\delta s_{i}-1}-\frac{1}{\sigma-\delta s_{i}-1} \frac{\delta^{2} s_{i}^{2}}{\sigma\left(\sigma-\delta s_{i}-1\right)+\left(\delta s_{i}\right)^{2}}\right] \\
& =P^{\delta}\left(\frac{\sigma-\delta s_{i}}{\sigma-\delta s_{i}-1}\right)^{-\sigma} a_{i}^{1-\sigma} \frac{\sigma}{\sigma\left(\sigma-\delta s_{i}-1\right)+\left(\delta s_{i}\right)^{2}}
\end{aligned}
$$

Due to the relationship between $p_{m, i}$ and $p_{i}$ shown in equation (13), these results are sufficient to solve for the total marginal profitability of increasing product span:

$$
\frac{\partial \pi_{i}\left(\iota_{n, i}, \iota_{m, i}, n_{i}, m_{i}\right)}{\partial n_{i}}=\pi_{i, n}\left(n_{i}, m_{i}\right) \equiv \Lambda_{i}\left[s_{i}\left(n_{i}\right)\right]+\tau^{1-\sigma} \Lambda_{i}\left[s_{F, i}\left(n_{i}, m_{i}\right)\right]
$$

where $\pi_{i, n}\left(n_{i}, m_{i}\right)$ is the marginal profit of $n_{i}$. We can solve analogously for an increase in the foreign subsidiary product span, which was also solve for above in section $(\mathrm{C})$. As before we get

$$
\frac{\partial \pi_{i}\left(\iota_{n, i}, \iota_{m, i}, n_{i}, m_{i}\right)}{\partial m_{i}}=\pi_{i, m}\left(n_{i}, m_{i}\right) \equiv\left(1-\tau^{1-\sigma}\right) \Lambda_{i}\left[s_{F, i}\left(n_{i}, m_{i}\right)\right]
$$

where we define $\pi_{i, m}\left(n_{i}, m_{i}\right)$ as the marginal profit of $m_{i}$. Therefore $\pi_{i, n}\left(n_{i}, m_{i}\right)$ is declining in $n_{i}$ while $\pi_{i, m}\left(n_{i}, m_{i}\right)$ is declining in $m_{i}$.

The above first-order conditions can be expressed as:

$$
\begin{gathered}
\zeta_{n, i} \phi_{n}^{\prime}\left(\iota_{n, i}\right)=1, \\
\zeta_{m, i} \phi_{m}^{\prime}\left(\iota_{m, i}\right)=1, \\
\dot{\zeta}_{n, i}=(r+\theta) \zeta_{n, i}-\Lambda_{i}\left[s_{i}\left(n_{i}\right)\right]-\tau^{1-\sigma} \Lambda_{i}\left[s_{F, i}\left(n_{i}, m_{i}\right)\right], \\
\dot{\zeta}_{m, i}=(r+\theta) \zeta_{m, i}-\left(1-\tau^{1-\sigma}\right) \Lambda_{i}\left[s_{F, i}\left(n_{i}, m_{i}\right)\right] .
\end{gathered}
$$

We can now use (45) and (46) to solve the investment levels $\iota_{n, i}$ and $\iota_{m, i}$,

$$
\begin{gathered}
\iota_{n, i}=\varphi_{n}\left(\zeta_{n, i}^{-1}\right), \\
\iota_{m, i}=\varphi_{m}\left(\zeta_{m, i}^{-1}\right),
\end{gathered}
$$

where $\varphi_{n}(\cdot)$ is the inverse of $\phi_{n}^{\prime}(\cdot)$ and $\varphi_{m}(\cdot)$ is the inverse of $\phi_{m}^{\prime}(\cdot)$. Substituting these functions into (37), (36), (47) and (48) yields an autonomous system of four differential equations with two initial conditions, $n_{i}^{0}$ and $m_{i}^{0}$ and free choices of $\zeta_{i}(0)$ and $\zeta_{m, i}(0)$ shown below:

$$
\begin{gathered}
\dot{\zeta}_{m, i}=(r+\theta) \zeta_{m, i}-\left(1-\tau^{1-\sigma}\right) \Lambda_{i}\left\{s_{i}\left[\left(n_{i}-m_{i}\right) \tau^{1-\sigma}+m_{i}\right]\right\} \\
\dot{m}_{i}=\phi_{m}\left[\varphi_{m}\left(\zeta_{m, i}^{-1}\right)\right]-\theta m_{i}, \\
\dot{\zeta}_{n, i}=(r+\theta) \zeta_{n, i}-\Lambda_{i}\left[s_{i}\left(n_{i}\right)\right]-\tau^{1-\sigma} \Lambda_{i}\left\{s_{i}\left[\left(n_{i}-m_{i}\right) \tau^{1-\sigma}+m_{i}\right]\right\}
\end{gathered}
$$




$$
\dot{n}_{i}=\phi_{n}\left[\varphi_{n}\left(\zeta_{n, i}^{-1}\right)\right]-\theta n_{i}
$$

\section{E Saddle Path Stability}

The four differential equations derived at the end of the previous section satisfy local saddle-path stability if its linearized representation around a steady state has two positive and two negative characteristic roots, because the dynamic system has two state variables and two jump variables. Let the steady state values be $\tilde{\zeta}_{m, i}, \tilde{\zeta}_{n, i}, \tilde{m}_{i}, \tilde{n}_{i}, \tilde{s}_{F, i}$ and $\tilde{s}_{i}$. Then the linearized system is

$$
\dot{\mathbf{y}}=A(\mathbf{y}-\tilde{\mathbf{y}})
$$

where

$$
\mathbf{y}=\left(\begin{array}{c}
\zeta_{m, i} \\
m_{i} \\
\zeta_{n, i} \\
n_{i}
\end{array}\right)
$$

$\tilde{\mathbf{y}}$ is the steady state value of $\mathbf{y}$ and $A$ is the matrix

$$
\begin{gathered}
A=\left(\begin{array}{cccc}
r+\theta & a_{12} & 0 & a_{14} \\
a_{21} & -\theta & 0 & 0 \\
0 & a_{32} & r+\theta & a_{34} \\
0 & 0 & a_{43} & -\theta
\end{array}\right), \\
a_{12}=-\left(1-\tau^{1-\sigma}\right)^{2} \Lambda_{i}^{\prime}\left(\tilde{s}_{F, i}\right) s_{i}^{\prime}\left[\left(\tilde{n}_{i}-\tilde{m}_{i}\right) \tau^{1-\sigma}+\tilde{m}_{i}\right], \\
a_{14}=-\left(1-\tau^{1-\sigma}\right) \tau^{1-\sigma} \Lambda_{i}^{\prime}\left(\tilde{s}_{F, i}\right) s_{i}^{\prime}\left[\left(\tilde{n}_{i}-\tilde{m}_{i}\right) \tau^{1-\sigma}+\tilde{m}_{i}\right], \\
a_{21}=-\phi_{m}^{\prime}\left[\varphi_{m}\left(\tilde{\zeta}_{m, i}^{-1}\right)\right] \varphi_{m}^{\prime}\left(\tilde{\zeta}_{m, i}^{-1}\right) \tilde{\zeta}_{m, i}^{-2}, \\
a_{34}=-\Lambda_{i}^{\prime}\left(\tilde{s}_{i}\right) s_{i}^{\prime}\left(\tilde{n}_{i}\right)-\tau^{2(1-\sigma)} \Lambda_{i}^{\prime}\left(\tilde{s}_{F, i}\right) s_{i}^{\prime}\left[\left(\tilde{n}_{i}-\tilde{m}_{i}\right) \tau^{1-\sigma}+\tilde{m}_{i}\right], \\
a_{43}=-\phi_{n}^{\prime}\left[\varphi_{n}\left(\tilde{\zeta}_{n, i}^{-1}\right)\right] \varphi_{n}^{\prime}\left(\tilde{\zeta}_{n, i}^{-1}\right) \tilde{\zeta}_{n, i}^{-2} .
\end{gathered}
$$

Note that all the $a_{i j}$ s are positive.

Every characteristic roots $\lambda$ of the matrix $A$ satisfies

$$
\operatorname{det}\left(\begin{array}{cccc}
r+\theta-\lambda & a_{12} & 0 & a_{14} \\
a_{21} & -\theta-\lambda & 0 & 0 \\
0 & a_{32} & r+\theta-\lambda & a_{34} \\
0 & 0 & a_{43} & -\theta-\lambda
\end{array}\right)=0,
$$


Or

$$
q^{2}+b q+c=0
$$

where

$$
\begin{gathered}
q:=(r+\theta-\lambda)(\theta+\lambda), \\
b:=a_{34} a_{43}+a_{21} a_{12}, \\
c:=a_{21} a_{43}\left(a_{12} a_{34}-a_{14} a_{32}\right) .
\end{gathered}
$$

Note however that $b>0$ and

$$
a_{12} a_{34}-a_{14} a_{32}=\left(1-\tau^{1-\sigma}\right)^{2} \Lambda_{i}^{\prime}\left(\tilde{s}_{F, i}\right) s_{i}^{\prime}\left[\left(\tilde{n}_{i}-\tilde{m}_{i}\right) \tau^{1-\sigma}+\tilde{m}_{i}\right] \Lambda_{i}^{\prime}\left(\tilde{s}_{i}\right) s_{i}^{\prime}\left(\tilde{n}_{i}\right)>0 .
$$

Therefore $c>0$ too. It therefore follows that

$$
q=\frac{1}{2}\left(-b \pm \sqrt{b^{2}-4 c}\right)<0 .
$$

This yields two real solutions to $q, q_{1}<0$ and $q_{2}<0$, because $b^{2}>4 c$. To prove the latter, not that $b^{2}>4 c$ if and only if

$$
a_{34}^{2} a_{43}^{2}+2 a_{21} a_{12} a_{34} a_{43}+a_{21}^{2} a_{12}^{2}+4 a_{21} a_{43} a_{14} a_{32}>4 a_{21} a_{12} a_{34} a_{43} .
$$

This expression can, however, be rewritten as

$$
\left(a_{21} a_{12}-a_{34} a_{43}\right)^{2}+4 a_{21} a_{43} a_{14} a_{32}>0,
$$

which is always satisfied. It follows that $\lambda_{i 1}$ and $\lambda_{i 2}$ that solve

$$
(r+\theta-\lambda)(\theta+\lambda)=-\lambda^{2}+r \lambda+\theta(r+\theta)=q_{i}
$$

have opposite signs for every $i=1,2$. That is, for every $q_{i}$ one characteristic root is positive and the other is negative. We conclude that the matrix $A$ has four characteristic roots, two negative and two positive. Therefore, our dynamic system is locally saddle-path stable.

\section{F Comparative Dynamics of $n_{i}$ and $m_{i}$}

In order to see how a change in $\tau$ affects investments, we concentrate on how the change affects the $M M$ and $N N$ curves. Differentiating equation (24), we confirm that an increase in $\tau$ shifts up the $M M$ curve: 


$$
\frac{\partial\left(1-\tau^{1-\sigma}\right) \Lambda_{i}\left\{s_{i}\left[\left(n_{i}-m_{i}\right) \tau^{1-\sigma}+m_{i}\right]\right\}}{\partial \tau}=(\sigma-1) \tau^{-\sigma} \Lambda_{i}+\left(1-\tau^{1-\sigma}\right)\left(n_{i}-m_{i}\right) \underbrace{\frac{\partial \Lambda_{i}}{\partial s_{F, i}}}_{<0} \underbrace{\frac{\partial s_{F, i}}{\partial \tau}}_{<0}>0 .
$$

This result and (24), i.e.,

$$
(r+\theta) \psi_{m, i}\left(m_{i}\right)=\left(1-\tau^{1-\sigma}\right) \Lambda_{i}\left\{s_{i}\left[\left(n_{i}-m_{i}\right) \tau^{1-\sigma}+m_{i}\right]\right\}
$$

imply that the $M M$ curve shifts up in response to a rise in trade costs. It follows that the foreign market share must be higher on the new $M M$ curve for a given level of $m_{i}$. In other words, the $M M$ curve shifts so that at every level of $m_{i}$ there is a higher value of $n_{i}$.

We can perform a similar analysis for the $N N$ curve,

$$
\begin{gathered}
\frac{\partial\left(\Lambda_{i}\left[s_{i}\left(n_{i}\right)\right]+\tau^{1-\sigma} \Lambda_{i}\left\{s_{i}\left[\left(n_{i}-m_{i}\right) \tau^{1-\sigma}+m_{i}\right]\right\}\right)}{\partial \tau}=\frac{\partial \tau^{1-\sigma} \Lambda_{i}\left\{s_{i}\left[\left(n_{i}-m_{i}\right) \tau^{1-\sigma}+m_{i}\right]\right\}}{\partial \tau} \\
=-(\sigma-1) \tau^{-\sigma} \Lambda_{i}\left(s_{F, i}\right)+\tau^{1-\sigma}\left(n_{i}-m_{i}\right) \frac{\partial \Lambda_{i}}{\partial s_{F, i}} \frac{\partial s_{F, i}}{\partial n_{F, i}} \frac{\partial\left[\left(n_{i}-m_{i}\right) \tau^{1-\sigma}+m_{i}\right]}{\partial \tau} .
\end{gathered}
$$

Rearranging:

$$
\begin{gathered}
\frac{\partial \tau^{1-\sigma} \Lambda_{i}\left[s_{i}\left(n_{F, i}\right)\right]}{\partial \tau} \frac{\tau^{\sigma} /(\sigma-1)}{\Lambda_{i}\left[s_{i}\left(n_{F, i}\right)\right]}=-1+\tau \frac{\left(n_{i}-m_{i}\right) /(\sigma-1)}{\Lambda_{i}\left[s_{i}\left(n_{F, i}\right)\right]} \frac{\partial \Lambda_{i}\left[s_{i}\left(n_{F, i}\right)\right]}{\partial s_{F, i}} \frac{\partial s_{F, i}}{\partial n_{F, i}} \frac{\partial\left[\left(n_{i}-m_{i}\right) \tau^{1-\sigma}+m_{i}\right]}{\partial \tau} \\
=-1+\eta_{\Lambda_{i}}\left(s_{F, i}\right) \eta_{s_{i}}\left(n_{F, i}\right) \frac{\tau^{1-\sigma}\left(n_{i}-m_{i}\right)}{\left(n_{i}-m_{i}\right) \tau^{1-\sigma}+m_{i}} .
\end{gathered}
$$

If this term is positive the $N N$ curve shift out; otherwise it shifts in.

The absolute value of the slope of the $M M$ curve is $c_{m m} / c_{m n}$ while the absolute value of the slope of the $N N$ curve is $c_{n m} / c_{n n}$, where $c_{n m}=c_{m n}$ and

$$
\begin{gathered}
c_{m m}=(r+\theta) \psi_{m, i}^{\prime}\left(m_{i}\right)-\left(1-\tau^{1-\sigma}\right)^{2} \Lambda_{i}^{\prime}\left(s_{F, i}\right) s_{i}^{\prime}\left(n_{F, i}\right), \\
c_{m n}=-\left(1-\tau^{1-\sigma}\right) \tau^{1-\sigma} \Lambda_{i}^{\prime}\left(s_{F, i}\right) s_{i}^{\prime}\left(n_{F, i}\right), \\
c_{n n}=(r+\theta) \psi_{n, i}^{\prime}\left(n_{i}\right)-\Lambda_{i}^{\prime}\left(s_{i}\right) s_{i}^{\prime}\left(n_{i}\right)-\left(\tau^{1-\sigma}\right)^{2} \Lambda_{i}^{\prime}\left(s_{F, i}\right) s_{i}^{\prime}\left(n_{F, i}\right) .
\end{gathered}
$$

It follows that the $M M$ curve is steeper. Next note that for a change in $a_{i}$ differentiation of the steady state equations (24) and (25) yields

$$
c_{m m} d m_{i}+c_{m n} d n_{i}=\left(1-\tau^{1-\sigma}\right) \tilde{\Lambda}_{i, a_{i}}\left(s_{F, i}\right) d a_{i}
$$




$$
c_{m n} d m_{i}+c_{n n} d n_{i}=\left[\tau^{1-\sigma} \tilde{\Lambda}_{i, a_{i}}\left(s_{F, i}\right)+\tilde{\Lambda}_{i, a_{i}}\left(s_{i}\right)\right] d a_{i},
$$

where

$$
\tilde{\Lambda}_{i, a_{i}}=\frac{\partial \Lambda_{i}}{\partial a_{i}}+\Lambda_{i}^{\prime} \frac{\partial s_{i}}{\partial a_{i}}
$$

Solving these equations we obtain

$$
\begin{aligned}
& \frac{d m_{i}}{d a_{i}} \frac{D}{1-\tau^{1-\sigma}}=\left[(r+\theta) \psi_{n, i}^{\prime}\left(n_{i}\right)-\Lambda_{i}^{\prime}\left(s_{i}\right) s_{i}^{\prime}\left(n_{i}\right)\right] \tilde{\Lambda}_{i, a_{i}}\left(s_{F, i}\right)+\tau^{1-\sigma} \Lambda_{i}^{\prime}\left(s_{F, i}\right) s_{i}^{\prime}\left(n_{F, i}\right) \tilde{\Lambda}_{i, a_{i}}\left(s_{i}\right), \\
& \frac{d n_{i}}{d a_{i}} D=(r+\theta) \psi_{m, i}^{\prime}\left(m_{i}\right)\left[\tau^{1-\sigma} \tilde{\Lambda}_{i, a_{i}}\left(s_{F, i}\right)+\tilde{\Lambda}_{i, a_{i}}\left(s_{i}\right)\right]-\left(1-\tau^{1-\sigma}\right)^{2} \Lambda_{i}^{\prime}\left(s_{F, i}\right) s_{i}^{\prime}\left(n_{F, i}\right) \tilde{\Lambda}_{i, a_{i}}\left(s_{i}\right),
\end{aligned}
$$

where $D=c_{m m} c_{n n}-c_{m n}^{2}>0$. It follows that if $\tilde{\Lambda}_{i, a_{i}}\left(s_{F, i}\right)>0$ and $\tilde{\Lambda}_{i, a_{i}}\left(s_{i}\right)>0$ then $n_{i}$ is increasing in $a_{i}$ and therefore a productivity improvement reduces the steady state product span while if $\tilde{\Lambda}_{i, a_{i}}\left(s_{F, i}\right)<0$ and $\tilde{\Lambda}_{i, a_{i}}\left(s_{i}\right)<0$ then $n_{i}$ is declining in $a_{i}$ and therefore a productivity improvement increases the steady state product span. In general, when $\tilde{\Lambda}_{i, a_{i}}\left(s_{F, i}\right)$ and $\tilde{\Lambda}_{i, a_{i}}\left(s_{i}\right)$ have the same signs, $m_{i}$ may increase or decline when $a_{i}$ rises, depending on their relative size. Nevertheless, this solution implies

$$
\begin{aligned}
\frac{d n_{F, i}}{d a_{i}} D & =(r+\theta) \psi_{m, i}^{\prime}\left(m_{i}\right)\left[\tau^{1-\sigma} \tilde{\Lambda}_{i, a_{i}}\left(s_{F, i}\right)+\tilde{\Lambda}_{i, a_{i}}\left(s_{i}\right)\right] \tau^{1-\sigma} \\
& +\left[(r+\theta) \psi_{n, i}^{\prime}\left(n_{i}\right)-\Lambda_{i}^{\prime}\left(s_{i}\right) s_{i}^{\prime}\left(n_{i}\right)\right] \tilde{\Lambda}_{i, a_{i}}\left(s_{F, i}\right)\left(1-\tau^{1-\sigma}\right)^{2}
\end{aligned}
$$

Therefore the effective number of foreign products rises with $a_{i}$ when $\tilde{\Lambda}_{i, a_{i}}\left(s_{F, i}\right)>0$ and $\tilde{\Lambda}_{i, a_{i}}\left(s_{i}\right)>$ 0 and declines with $a_{i}$ when $\tilde{\Lambda}_{i, a_{i}}\left(s_{F, i}\right)<0$ and $\tilde{\Lambda}_{i, a_{i}}\left(s_{i}\right)<0$.

Next note from (24) and (25) that

$$
\begin{gathered}
(r+\theta) \psi_{m, i}^{\prime}\left(n_{i}\right) d m_{i}=\left(1-\tau^{1-\sigma}\right) d \Lambda_{i}\left(s_{F, i}\right) \\
=\left(1-\tau^{1-\sigma}\right) \frac{\partial \Lambda_{i}\left(s_{F, i}\right)}{\partial a_{i}} d a_{i}+\left(1-\tau^{1-\sigma}\right) \Lambda_{i}^{\prime}\left(s_{F, i}\right) d s_{F, i} \\
(r+\theta) \psi_{n, i}^{\prime}\left(n_{i}\right) d n_{i}=d \Lambda_{i}\left(s_{i}\right)+\tau^{1-\sigma} d \Lambda_{i}\left(s_{F, i}\right) \\
=\frac{\partial \Lambda_{i}\left(s_{i}\right)}{\partial a_{i}} d a_{i}+\Lambda_{i}^{\prime}\left(s_{i}\right) d s_{i}+\tau^{1-\sigma} \frac{\partial \Lambda_{i}\left(s_{F, i}\right)}{\partial a_{i}} d a_{i}+\tau^{1-\sigma} \Lambda_{i}^{\prime}\left(s_{F, i}\right) d s_{F, i}
\end{gathered}
$$

Therefore in the case in which an improvement in labor productivity reduces both $n_{i}$ and $n_{F, i}$, i.e., $s_{F, i}>s_{c}$, this implies that $\Lambda_{i}^{\prime}\left(s_{i}\right) d s_{i}+\Lambda_{i}^{\prime}\left(s_{F, i}\right) d s_{F, i}<0$. Therefore either $d s_{i}>0$ or $d s_{F, i}>0$. In other words, the market share has to increase in at least one country. Moreover, if $m_{i}$ declines, then $d s_{F, i}>0$, implying that the market share rises in the foreign country. 